\title{
A Review on Mechanisms for Piezoelectric-Based Energy Harvesters
}

\author{
Hassan Elahi ${ }^{*}+{ }^{+}\left(\mathbb{0}\right.$, Marco Eugeni $^{\dagger}$ and Paolo Gaudenzi ${ }^{\dagger}$ \\ Department of Mechanical and Aerospace Engineering, Sapienza University of Rome, Via Eudossiana 18, \\ 00184 Rome, Italy; marco.eugeni@uniroma1.it (M.E.); paolo.gaudenzi@uniroma1.it (P.G.) \\ * Correspondence: hassan.elahi@uniroma1.it; Tel.: +39-327-6544166 \\ t These authors contributed equally to this work.
}

Received: 23 May 2018; Accepted: 28 June 2018; Published: 14 July 2018

\begin{abstract}
From last few decades, piezoelectric materials have played a vital role as a mechanism of energy harvesting, as they have the tendency to absorb energy from the environment and transform it to electrical energy that can be used to drive electronic devices directly or indirectly. The power of electronic circuits has been cut down to nano or micro watts, which leads towards the development of self-designed piezoelectric transducers that can overcome power generation problems and can be self-powered. Moreover, piezoelectric energy harvesters (PEHs) can reduce the need for batteries, resulting in optimization of the weight of structures. These mechanisms are of great interest for many researchers, as piezoelectric transducers are capable of generating electric voltage in response to thermal, electrical, mechanical and electromagnetic input. In this review paper, Fluid Structure Interaction-based, human-based, and vibration-based energy harvesting mechanisms were studied. Moreover, qualitative and quantitative analysis of existing PEH mechanisms has been carried out.
\end{abstract}

Keywords: piezoelectric; energy harvesting; vibrations; aeroelastic; smart material; fluid structure interaction; piezoelectricity; review

\section{Introduction}

The phenomenon of energy harvesting based on piezoelectric transducers can be defined as the transformation of energy absorbed by a transducer from an operating environment to electric voltage that be used on the spot for actuation or stored in batteries for future usage [1-4]. As the world is shifting from electrical equipment to electronic devices due to the energy crisis, it is leading to a reduction in electrical power consumption, resulting in micro and nano powered electronic circuits [5-7]. Numerous researchers have focused on the usage of PEHs as self-powered sources over the storage of electric voltage in batteries because of the voltage drop [8,9]. Due to recent technological advancements, these harvesters are ideal to be used in micro electromechanical systems (MEMS), smart structures, structural health monitoring, and as wireless sensors for suborbital missions [10-14].

As a consequence of the energy crisis, many techniques have been developed to generate electric voltage [15-18]. These techniques have been used to generate power ranging from nano to mega watts [19-21]. These approaches to energy generation are dependent on their utilization. That is, industrial usage, domestic usage, or low-powered electronics actuation [22-25]. This review paper will focus on energy generation for low-powered circuits by piezoelectric (PZT) harvesters. Nano and micro watts of power can be generated from PZT harvesters by applying thermal [26], light [27], mechanical [28-30], fluid [31], and electrical [32] input. Out of these possible options, mechanical input is considered to be the most efficient because it can be easily provided as compared to other inputs [33-35]. The conversion of mechanical energy (from waste vibrations) into electrical energy can be done by electromagnetic [36-39], piezoelectric [33,40], or 
electrostatic [41-43] mechanisms of transduction. The piezoelectric transduction mechanism is the most efficient mechanism for microelectronics [44], wireless sensors [45], and nanoelectronics [46] because they are easy to fabricate $[47,48]$ and are able to harvest energy at variable frequencies [49-51]. This phenomenon was discovered by Pierre and Jacques Curie in 1880 [52] as having a direct effect (i.e., conversion of mechanical energy to electrical energy [53]), as expressed in Equation (1) [54] and a converse effect (i.e., the conversion of electrical energy to mechanical energy [55]), as expressed in Equation (2) [56]. Control techniques with/without piezoelectric sensors for different materials have been carried out [57-60]. Many researchers are working on super-capacitors to store electrical energy rather than conventional storage devices (i.e., electrical batteries or electrochemical capacitors [61]). They have the advantages of less maintenance, easy charging, and are more effective as compared to conventional batteries [61,62].

$$
\begin{aligned}
& D_{i}=e_{i j}^{\sigma} E_{j}+d_{i m}^{d} \sigma_{m}, \\
& \epsilon_{k}=d_{j k}^{c} E_{j}+S_{k m}^{E} \sigma_{m},
\end{aligned}
$$

where $D_{i}$ is the dielectric displacement vector, $\epsilon_{k}$ is the strain vector, $E_{j}$ is the applied electric field vector, $\sigma_{m}$ is the stress vector, $d_{i m}^{d}$ and $d_{j k}^{c}$ are piezoelectric coefficients for direct and converse effects of piezoelectricity, respectively, $e_{i j}^{\sigma}$ is the dielectric permittivity at constant stress, and $S_{k m}^{E}$ is the elastic compliance matrix at constant electric field. Piezoelectric material characteristics are expressed in Table 1. 
Table 1. Piezoelectric material properties.

\begin{tabular}{|c|c|c|c|c|c|c|c|c|c|c|}
\hline Coefficient & Units & PZT-5H [9] & PZT-5A [10] & PZT-8 [63] & $\mathrm{BaTiO}_{3}[64]$ & PIC-255 [65] & PVDF [9] & $\mathrm{ZnO}[66]$ & KNN [67] & AlN $[68]$ \\
\hline Piezoelectric charge constants $\left(d_{31}\right)$ & $10^{-12} \mathrm{~m} / \mathrm{V}$ & -274 & -171 & -97 & -33 & -180 & $18-24$ & - & - & - \\
\hline$d_{33}$ & $10^{-12} \mathrm{~m} / \mathrm{V}$ & 593 & 374 & 225 & 82 & 400 & -33 & - & 689 & - \\
\hline$d_{15}$ & $10^{-12} \mathrm{~m} / \mathrm{V}$ & 741 & 584 & 330 & 150 & 550 & - & - & - & - \\
\hline Density $(\rho)$ & $\mathrm{kg} / \mathrm{m}^{3}$ & 7500 & 7750 & 7600 & 5600 & 7800 & 946 & 566 & - & 3260 \\
\hline Curie temperature & ${ }^{\circ} \mathrm{C}$ & 193 & 350 & 300 & 123 & 350 & 195 & - & 432 & - \\
\hline Elastic modulus $(E)$ & $10^{10} \mathrm{~N} / \mathrm{m}^{2}$ & 6.2 & 6.5 & 6.3 & 1.16 & - & 0.418 & - & - & - \\
\hline Mechanical quality factor $\left(Q_{m}\right)$ & - & 30 & 80 & 98 & 130 & 80 & 17.2 & - & 85 & - \\
\hline Poisson's ratio $(u)$ & - & 0.31 & 0.31 & 0.31 & 0.35 & 0.34 & 0.34 & 0.358 & - & 0.24 \\
\hline
\end{tabular}


Figure 1 expresses the harvesting electrical circuit of a piezoelectric energy harvester (PEH) for thermo-electro-mechanical shocking; decade resistors are used to shock the PEH at variable external resistances, a DC motor is used to shock the PEH mechanically, an iron filament is used to shock PEH thermally, a mica sheet is used to insulate the PEH, and an oscilloscope is used to measure the output voltage in order to calculate the energy harvested by the PEH [64]. For simple mechanical-based PEH, resistance and capacitance are in parallel to the piezoelectric patch, as shown in Figure 2 [69].

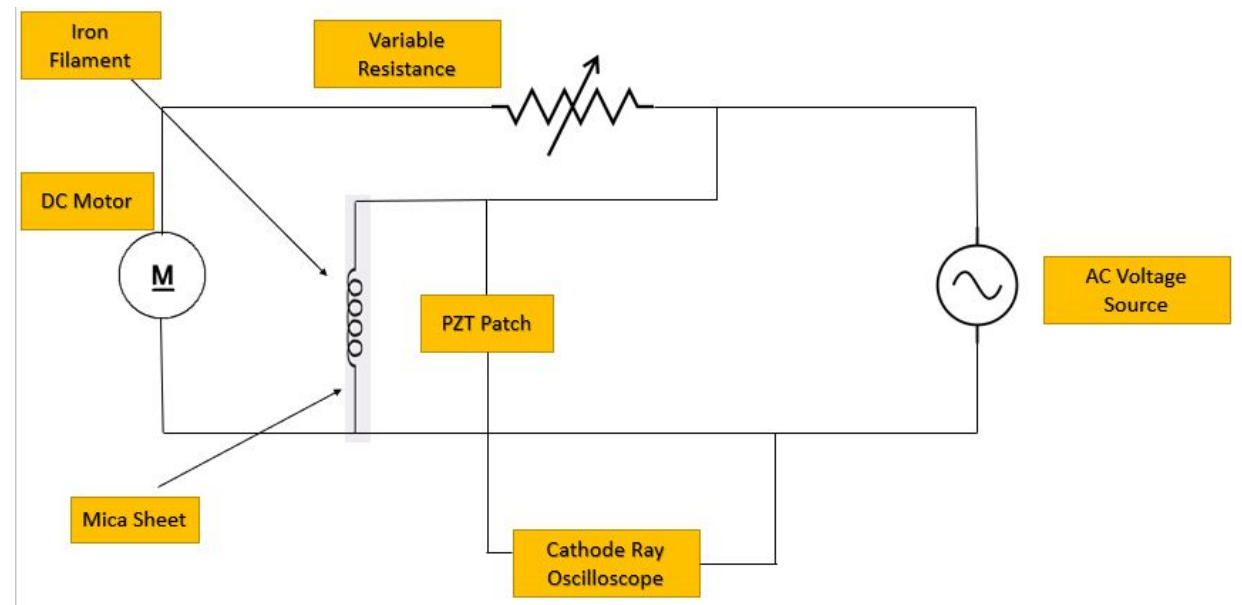

Figure 1. Electrical circuit of a thermo-electro-mechanical-based piezoelectric energy harvester (PEH) (iron filament is used for thermal shocking; function generator is used for electrical shocking; DC motor with CAM shaft is used for mechanical loading; decade box is used to shock PZT externally at variable resistance; PZT has internal resistance $\mathrm{R}_{o}$; mica sheet is used for thermal and electrical insulation; Cathode ray oscilloscope (CRO) is used for data acquisition).

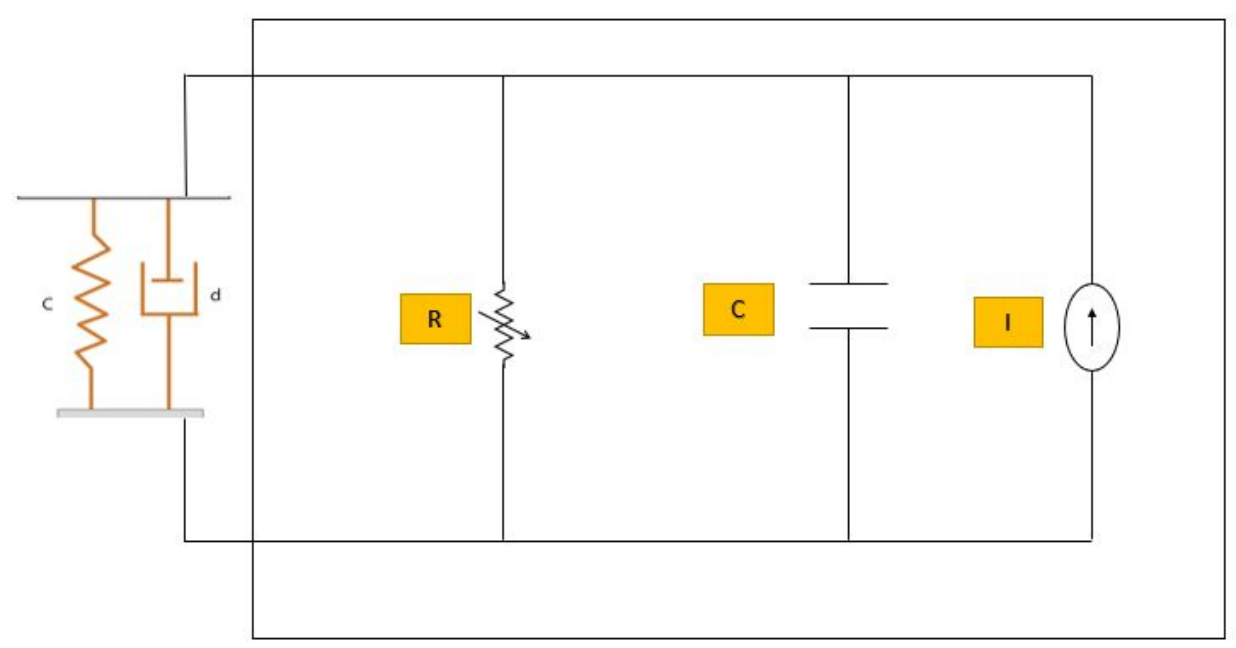

Figure 2. Electrical circuit of mechanical-based PEH. PZT is shocked mechanically (i.e., direct effect of piezoelectricity), which overcomes the internal resistance $R_{0}$, the poling phenomenon occurs, and energy is generated.

PEH can be a very suitable alternative energy source compared to traditional ones, and has vital applications in the area of automotive, aerospace, and defence sectors due to micro-scale devices [70]. They can operate various sensors and actuators. Moreover, they have very compact structure and are an environmentally friendly source of energy generation. That is why piezoelectric patches are widely used in various optical devices [71], space missions [10], biomedical devices [72], mechanical/civil structures [73], and precise measurement tools [74]. PEHs are preferred because 
of their flexibility, low electromagnetic interference, high positioning, and high torque-to-volume ratio $[75,76]$. A PEH is composed of three major components one, the piezoelectric patch that is responsible for converting environmental input (i.e., fluid structure interaction (FSI), biomechanical, vibration, etc.) into alternating current; two, the storage unit that can be a super capacitor or a battery to store the charge generated by the PEH; three, the modulating circuit that is responsible for the conversion of AC into DC [77]. The storage unit can be ignored in order to utilize energy directly from the PEH $[77,78]$.

The need for PEHs arises because batteries have less operational life than the circuit. In many conditions, replacement or maintenance of the battery is impossible and the cost of the battery is very costly for the operation. The usage of a battery may result in maintenance issues when they are operated in harsh environments (i.e., high-altitude places, cold or hot climates, icy or snowy regions), as these conditions lead to damaged battery life. In such cases, even recycling of the batteries is a problem as well as an environmental hazard (especially lead ion batteries). In these conditions, one of the solutions is to use different external energy sources (i.e., PEHs) so that durability of the battery can be increased [79]. These issues lead to the utilization of PEHs as an additional energy source which can assist electronic devices directly or indirectly via batteries by increasing their operational life time [70]. Many researchers have worked on alternate sources of micro electric voltage generation for wireless sensors by using the electromagnetic phenomenon. Mann and Sims worked on improving the effectiveness of harvesters by inducing nonlinearities experimentally and numerically [80]. Mahmoudi et al. worked on nonlinearities induced by a vibration-based piezo-electromagnetic harvester [81]. The phenomenon of inducing nonlinearities is of great interest for many researchers [82-85].

The efficiency of the harvested energy for direct piezoelectricity can be analyzed by calculating the difference of mechanical energy converted into electrical energy and the loss in energy conversion [14,86-88]. This harvesting mechanism is dependent on the medium of interaction [89-92]; that is, the transformation of kinetic energy to the PZT transducer [93-95]. These media may be mechanical vibrations [51,96,97], fluid-structure interaction [98,99], and thermal interaction [100,101]. In this review paper, PEH mechanisms based on fluid-structure interaction, human based interaction, and vibration are studied. Qualitative and quantitative analysis of existing PEH mechanisms has been carried out. Section 1 is a brief introduction to PEH mechanisms. Section 2 elaborates the fluid-structure interaction mechanisms. Section 3 elaborates human-based $\mathrm{PEH}$, and Section 4 describes vibration-based PEH.

\section{Fluid-Structure Interaction-Based PEH}

As a consequence of mega products in to micro products, the development of aerospace structures that utilize clean, renewable energy and are self sufficient of energy production are encouraged [102] (i.e., smart structures) $[103,104]$. Beginning in the last decade, fluid-surface interaction-based PEHs have been of great interest for many researchers [105-107]. In these, the PZT harvester is placed in a fluid flow for energy harvesting, it undergoes limit cycle oscillations (LCOs) that can be converted to output electrical energy to operate electronic devices or for storage [108]. In the fields of aerospace and civil engineering, when the structure is subjected to fluid flow $[109,110]$, it may undergo the phenomenon of bifurcations [111-113], LCO [114-116], internal resonance [117,118], and disorder motion $[119,120]$. In mega structures, aerodynamic phenomena such as vortex-induced vibrations (VIVs) [121], flutter [106,122], and galloping [123] may result in excessive vibrations that can damage or even destroy the structures [124]. The overall scheme for FSI-based PEHs is expressed in Figure 3 [125]. These effects are described below: 


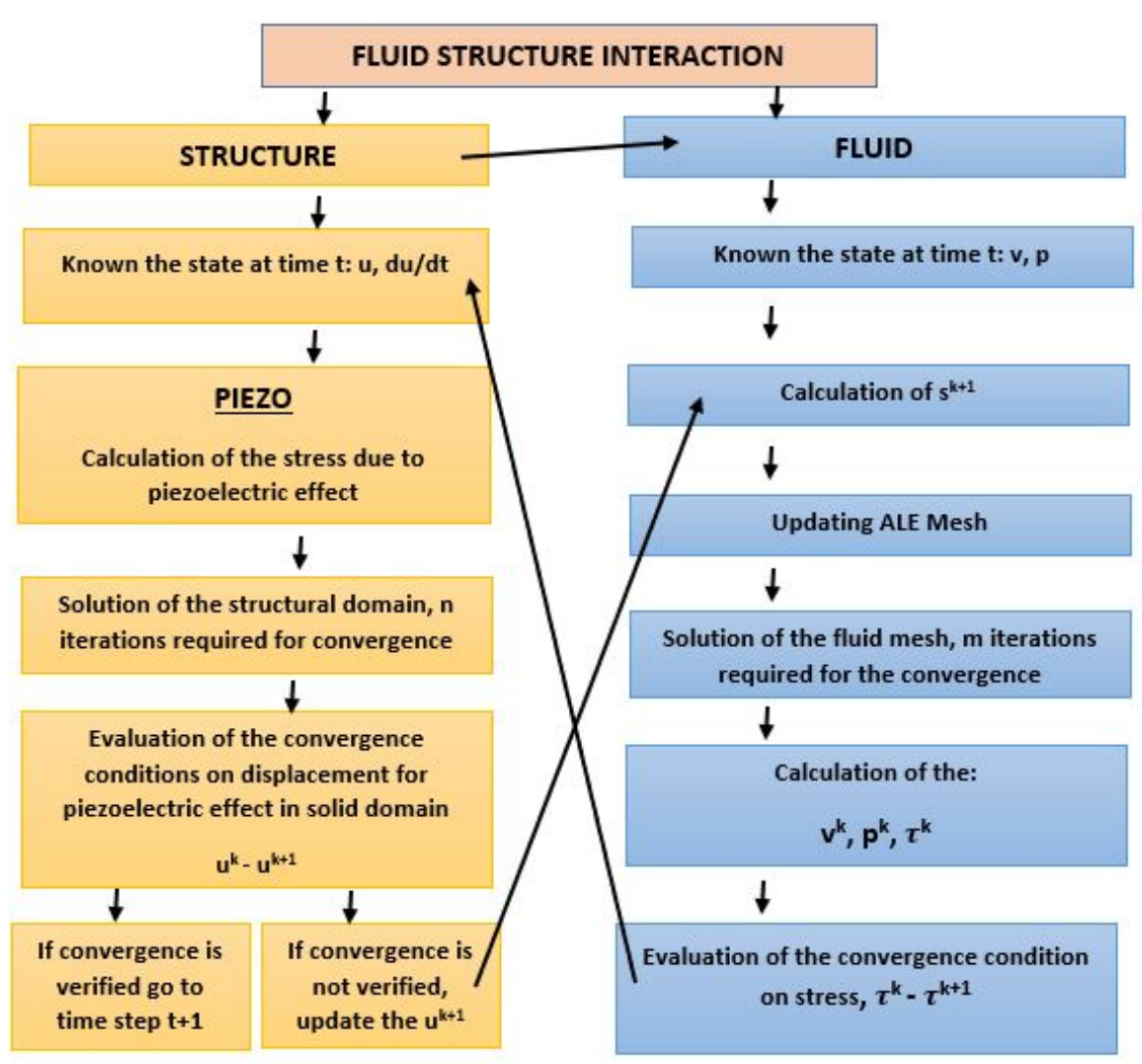

Figure 3. Overall scheme for fluid-structure interaction (FSI)-based PEH [125].

\subsection{Vortex-Induced Vibrations-Based PEH}

Recently, many researchers have been working on the development of piezoelectric energy harvesters that can absorb energy from the environment (i.e., VIV) and transform it into useful electrical energy $[90,126-128]$. The most commonly used process is attaching the PZT patch to the the fixed end of an elastic cantilever beam and attaching the circular cylinder to the free end of the beam, as shown in Figure $4[127,128]$. The PZT patch is shocked with external resistance as it has a vital effect on the amplitude of oscillations, the coefficient of lift, and the output energy generated by the harvester [124]. Mehmood performed numerical simulations by attaching a PZT patch to the transverse degree of freedom (DOF) by taking into account Reynolds numbers (Re) ranging from 96-118 and resistance from $500 \Omega$ to $5 \mathrm{M} \Omega$ [126]. Re are selected on the basis that they can accumulate pre-synchronization, synchronization, and post-synchronization regimes, as shown in Figure 5 [126]. A schematic of this proposed mechanism is expressed in Figure 6 [126], where $U_{\infty}$ is the free stream velocity, $C$ is the structural damping, $K$ is the structural stiffness, and $R$ is the electric resistance applied. Dai demonstrated based on Galerkin discretization that the first four modes are necessary to evaluate the performance of the harvester correctly [128]. Moreover, both linear and nonlinear analyses have been performed in order to analyze the efficiency of the system, and it was observed that when the flow was at the synchronization region, electromechanical damping associated to it decreased, which resulted in an increase of the harvested energy [127]. Franzini carried out a sensitivity study that can influence the dimensionless quantities characterizing the PZT harvesters and proposed a $50 \%$ increase in the efficiency of the harvester for a particular reduced frequency [121]. The enhancement of the voltage generated was carried out by optimizing the parameters based on a genetic algorithm [129]. The efficiency of the energy harvested by VIV can be analyzed for 1 DOF by Equation (3) [121]:

$$
\eta_{e l, x}=\frac{4 \pi^{2}}{U_{r}^{3}} \frac{\left(\theta^{*}\right)^{2}}{f^{*}} \frac{\sigma_{2, x}}{\sigma_{1, x}}\left(m^{*}+C_{\alpha}\right) v_{x}^{2}
$$


where $\theta^{*}=\theta_{x} / \theta_{y}, f^{*}=w_{n, x} / w_{n, x}, \eta_{e l, x}$ is the dimensionless electric power harvested at cross-wise and in-line harvesters, $U_{r}$ is the reduced velocity, $\sigma_{2, x}, \sigma_{1, x}$ are the dimensionless quantities related to the piezoelectric harvesters, $\theta_{x}, \theta_{y}$ are the electro-mechanical coupling constants, $w_{n, x}, w_{n, y}$ are the cylinder's natural frequencies, $m^{*}$ and $C_{\alpha}$ are the mass parameter and potential added mass coefficient, respectively.

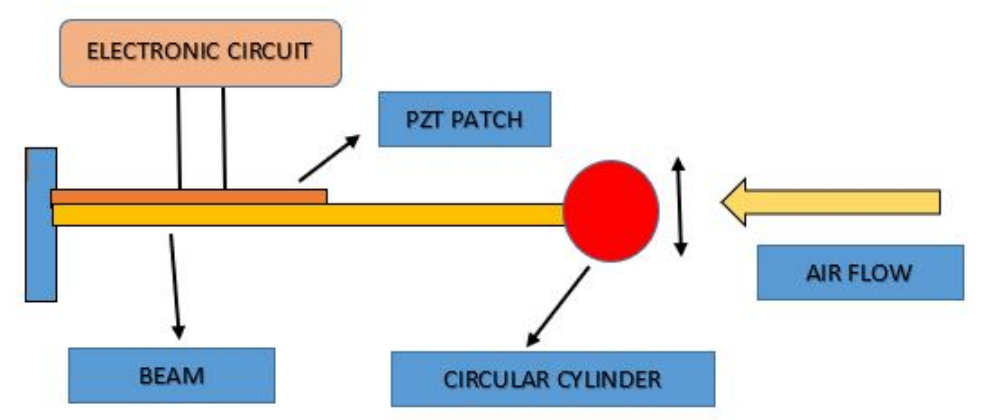

Figure 4. Mechanism of a vortex-induced vibration (VIV)-based PEH.

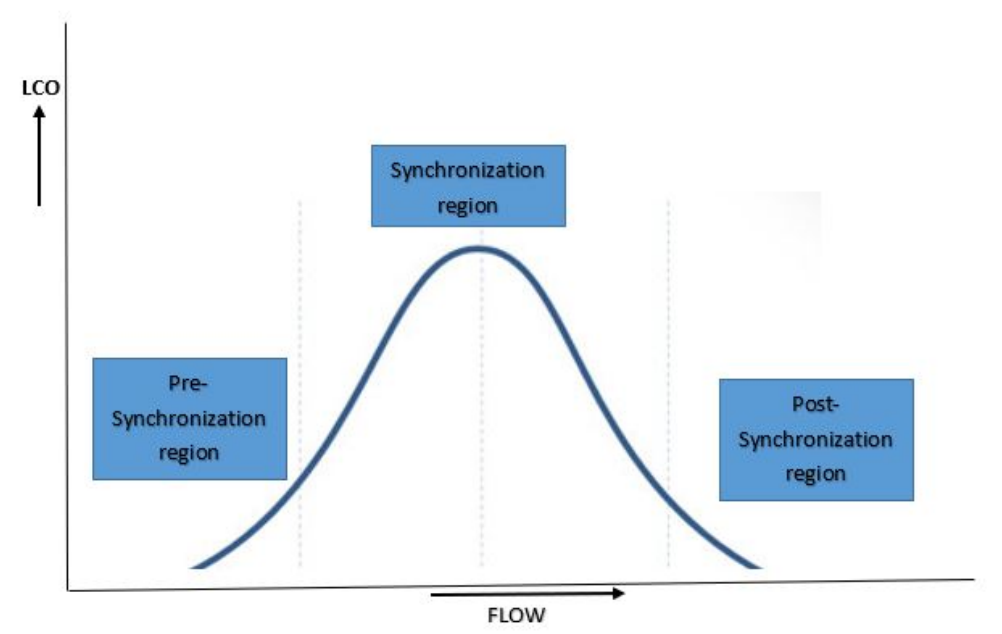

Figure 5. Bifurcation diagram (in dynamical system, this figure is representing data points that have been approched or approximated by a system as a bifurcation parameter in a system revealing bifurcation theory).

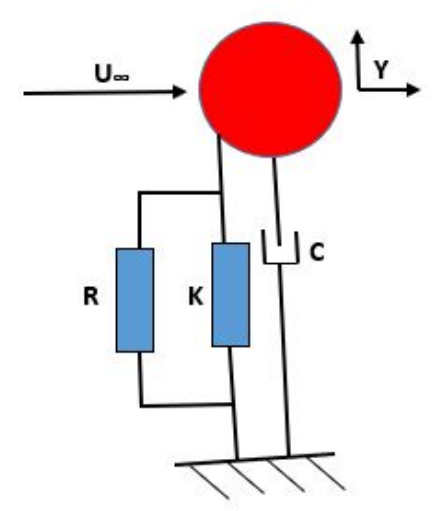

Figure 6. Cylinder-based piezoaeroelastic energy harvester subjected to free stream velocity $U_{\infty} ; \mathrm{R}$ is the electrical load resistance; $\mathrm{C}$ and $\mathrm{K}$ are structural damping and stiffness. 
Franzini carried out a numerical solution of PEH from VIV via the dynamics of a rigid cylinder mounted at the end of an elastic beam attached with a piezoelctric patch. He considered a wake oscillator model as hydrodynamic load, coupling the solid and electric oscillators as considered by linear constitutive equations, and the dynamics of the FSI-based PEH system was investigated for the influence of an additional structural DOF (i.e., in-line oscillations). He demonstrated that the efficiency of PEH could be increased up to $50 \%$ at any particular reduced frequency [121].

Experimental studies were carried out for PEH exposed to VIV via pivoted rigid cylinder. The sensitivity study for PEH efficiency was carried out for different parameters. It was concluded that it is not compulsory that PEH increases by increasing Re efficiency; the maximum power harvested was $\approx 60 \mathrm{~mW}$ [130]. Another experimental study was carried out in which a secondary cylinder was placed between the generator and the primary cylinder exposed to VIV. In this way, the free-stream velocity range was enhanced and energy harvesting became more effective. The electric tension achieved reached $9 \mathrm{~V}$ [131]. Soti numerically investigated the dynamics of a cylinder attached to a magnet. The maximum harvested dimensionless power was 0.13 [132].

An investigation of the energy harvested by a PEH from VIV was carried out in a wind tunnel. The rigid cylinder was mounted to the free end of an elastic beam attached with a piezoelectric patch, nonlinearities were introduced into the system by two magnets. These nonlinearities could increase the efficiency of the harvester by up to $29 \%$ [133]. Bunzel and Franzini numerically investigated the harvesting of energy for the first time from 2 DOF VIV by considering a wake oscillator model. The cylinder was mounted on an elastic beam and oscillated in both directions (i.e., cross-wise and in-line directions). The cylinder was coupled to a piezoelectric harvester and it was observed that by changing the value of $\sigma_{1}$ from 0.33 to 3.3 with no change in amplitude of oscillations, the harvested energy was decreased by 0.1 [134].

\subsection{Flutter-Based PEH}

One of the fundamental tasks of aeroelastic control design is to minimize flutter $[135,136]$. A flutter-based piezoaeroelastic energy harvester schematic is represented in Figure 7 [124]. The PZT patch is attached on the fixed end of an elastic cantilever beam with an external circuit from which it can be shocked with variable resistance. This elastic beam is subjected to flow. By increasing the flow, there arises a specific speed (i.e., flutter speed) at which, due to aerodynamic effects, structural damping is not enough to damp motions [106,137-140]. Due to nonlinearities, sub-critical or super-critical Hopf bifurcation can take place [141-143], as shown in Figure 8, and a schematic of the piezoaeroelastic system is expressed in Figure 9. For energy harvesting, a large symmetric flutter state is identified as the most suitable [144]. The governing equations are expressed in Equations (4)-(6) [138,145-147]:

$$
\begin{gathered}
m_{T} \ddot{h}+m_{W} x_{\alpha} b \ddot{\alpha}+c_{h} \dot{h}+k_{h}(h) h-\theta V=-L, \\
m_{W} x_{\alpha} b \ddot{h}+I_{\alpha} \ddot{\alpha}+c_{\alpha} \dot{\alpha}+k_{\alpha}(\alpha) \alpha=M, \\
C_{p} \dot{V}+\frac{V}{R}+K_{M E} \dot{h}=0,
\end{gathered}
$$

where $h$ is the plunge deflection, $\alpha$ is the pitch angle, $m_{T}$ is the total mass of the wing with its support structure, $m_{W}$ is the wing mass alone, $I_{\alpha}$ is the mass moment of inertia about the elastic axis, $b$ is the half chord length, $x_{\alpha}$ is the dimensionless distance between the center of mass and the elastic axis, $c_{h}$ and $c_{\alpha}$ are, respectively, the plunge and pitch structural damping coefficients, $L$ and $M$ are the aerodynamic lift and moment about the elastic axis, $R$ is the load resistance, $V$ is the voltage across this load resistance, $C_{p}$ is the capacitance of the piezoelectric layer, $\theta$ and $K_{M E}$ are electromechanical coupling terms, and $k_{h}$ and $k_{\alpha}$ are the structural stiffness for the plunge and pitch motions, respectively [138]. 


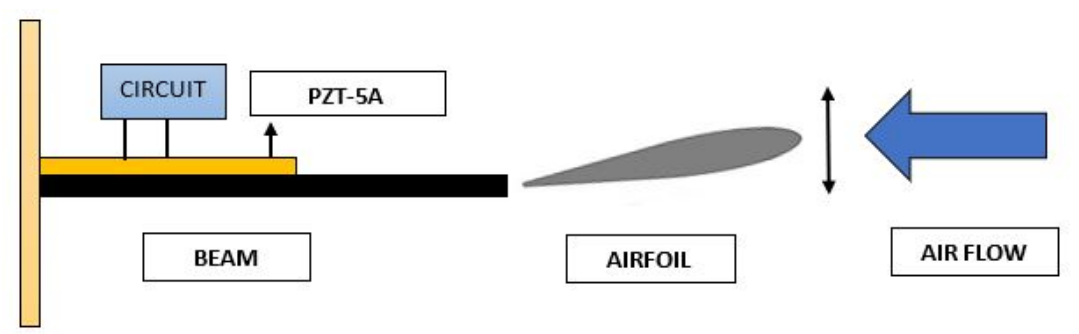

Figure 7. Flutter-based piezoaeroelastic energy harvester schematic.

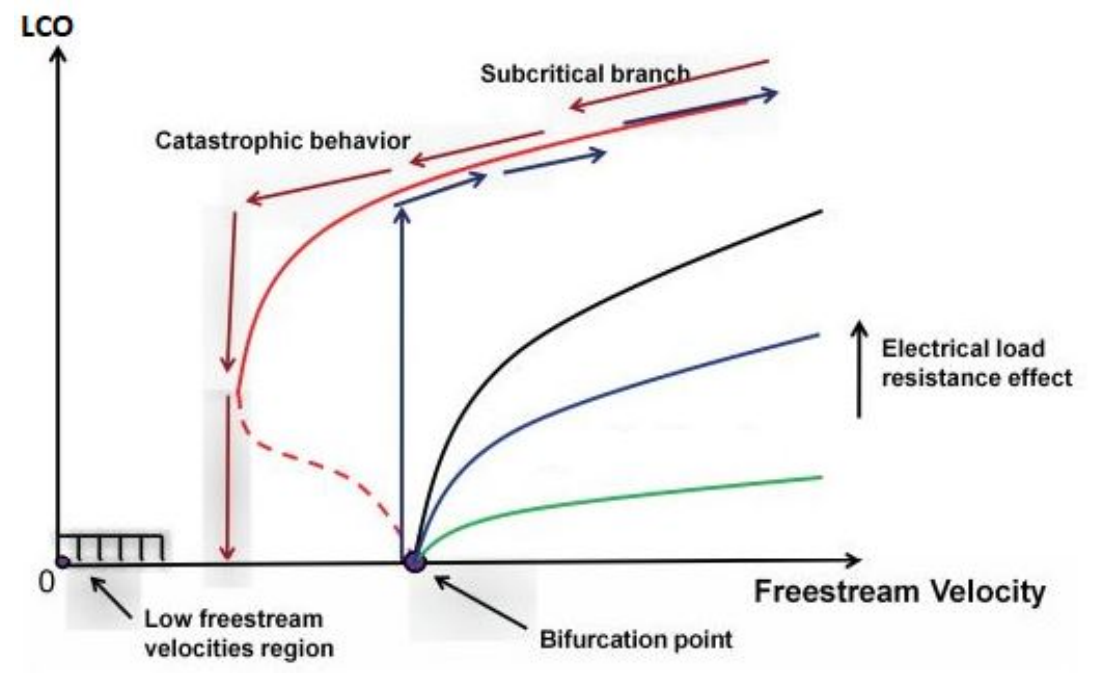

Figure 8. Bifurcation diagram [148]. In a dynamical system, this figure represents data points that have been approached or approximated by a system as a bifurcation parameter in a system revealing bifurcation theory. LCO: limit cycle oscillation.

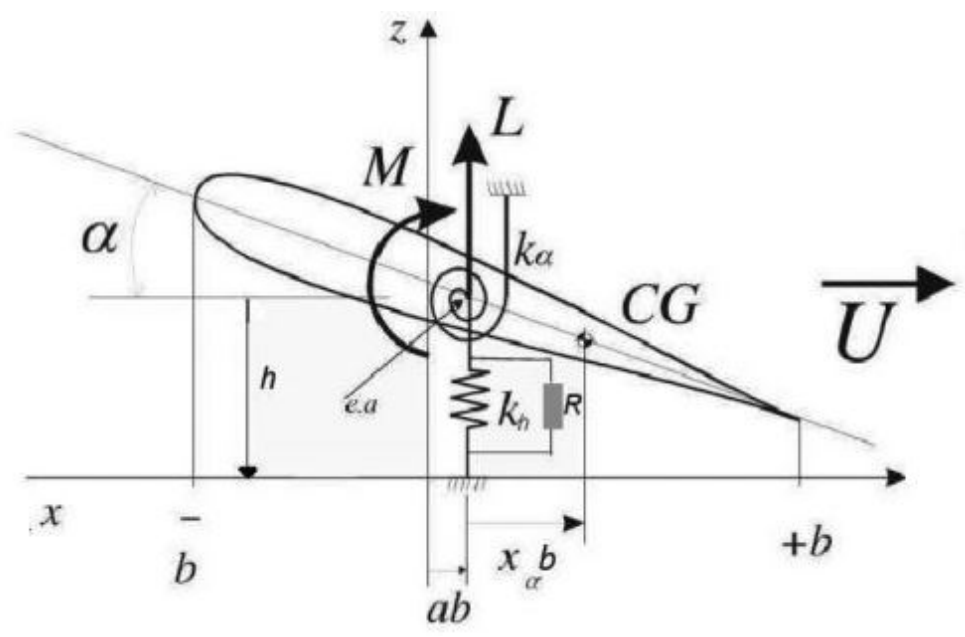

Figure 9. Piezoaeroelastic system schematic [148]. A three-degrees of freedom (DOF) airfoil supported elastically by linear plunge and linear torsional spring.

Eugeni proposed an energy harvester based on the flutter mechanism experienced by a wing. The energy transmitted from the flow to the structure in this self-excited motion of the aeroelastic system is harvested by a PZT patch (i.e., single-layer lead zirconate titanate) applied at the fixed end of the wing. In particular, the wing is equipped with a control surface (flap). This choice was 
dictated thinking of the realization of the harvester prototype because it is much easier to design the nonlinearities in the connection between the main wing and flap with respect to those associated to the principal structure. In Figure 10, a sketch of the harvesting mechanism is proposed where the single-layer configuration of the PZT harvester is also stressed [149].
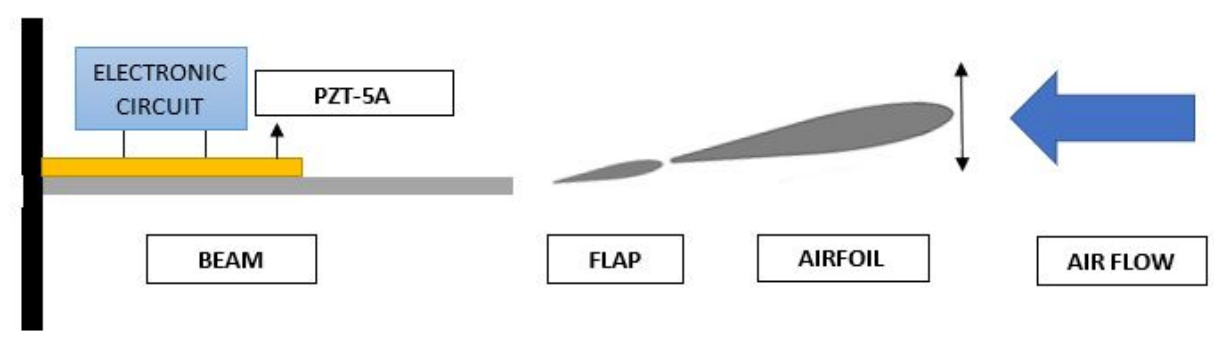

Figure 10. Aeroelastic energy harvester model [149]. A 3-DOF airfoil is constrained with flap motion and is subjected to the airfoil supported elastically by linear plunge and linear torsional spring.

Bahaadini studied the instabilities of flowing fluid in nanotubes of piezoelectric material, and observed that both divergence and flutter were the reason for instability of nanotubes with supported ends for fluid flow. These instabilities can lead to significant energy harvesting. By decreasing the critical flow velocities, an increase in piezoelectric voltage was observed that resulted in a decrease of the system stability [150]. Thiago investigated the flutter instabilities for piezoelectric transducers-based composite panels (tow steered). In order to increase aeroelastic instabilities, he presented optimized size and position using a differential evolution algorithm for composite panels and piezoelectric transducers [135]. The feedback control system for active flutter control were chosen on hit and trial methods which take a great deal of time and are not accurate. Song presented a genetic algorithm which is optimized and smart enough to investigate the thermal flutter control of laminated composite panels in supersonic airflow. The piezoelectric actuators' feedback gains were shown as chromosomes [151]. Sousa investigated the aeroelastic behavior of a typical section, the combined effects of passive pseudo-elastic hysteresis of shape memory springs and piezoelectric material on it. Due to this combined effect, the post-flutter airflow speed range with stable LCOs was increased, which could prove to be an effective piezoaeroelastic harvester [106].

\subsection{Galloping-Based PEH}

In order to harvest energy from FSI using PZT, two types of galloping mechanisms can be used: transverse galloping [91,152-155] and wake galloping [91,156,157], as shown in Figures 11 and 12, respectively. The PZT patch is attached on the fixed end of an elastic cantilever beam with an external circuit from which it can be shocked with variable resistance. The prismatic structure of any shape (i.e., square, D-shape, or triangle) is attached to the free end of beam, which is subjected to airflow, and oscillations are produced in the direction normal to the flow [158-160]. In wake galloping-based $\mathrm{PEH}$, a bluff body is attached to the free end of the beam and another bluff body is placed in front of it. This phenomenon is dependent on the position of the front bluff body, and vibrations are induced in the spacing distance [161-163]. The galloping mechanism arises when the aerodynamic lift coefficient at steady state has a negative derivative [159]. Upon increasing or decreasing the air flow, the flutter-based harvester and the galloping-based harvester have the same bifurcation diagram. The difference between these two mechanisms is that the flutter phenomenon is basically a 2 or 3 DOF system, while the galloping phenomenon is of 1 DOF system [124,164].

Zhao compared the performance of a standard circuit with a synchronized charge extraction circuit in a galloping-based piezoelectric energy harvester. He demonstrated three advantages of using synchronized charge extraction: The electrical load is independent of output power, which reduces the requirement of impedance matching, resulting in flexible practical applications of galloping-based 
piezoelectric energy harvester systems; this circuit saves PZT patches by $75 \%$; and it increases the fatigue life of a system as the displacement amplitude reduces [165]. The quantitative analysis of various FSI-based PEHs is represented in Table 2.

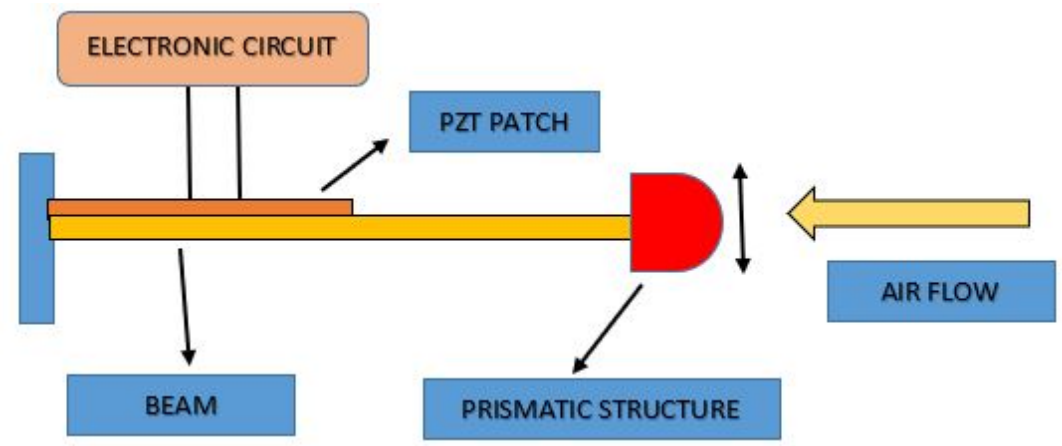

Figure 11. Transverse galloping-based PEH schematic. A D-shaped prismatic structure is subjected to airflow, attached at the end of an elastic cantilever beam.

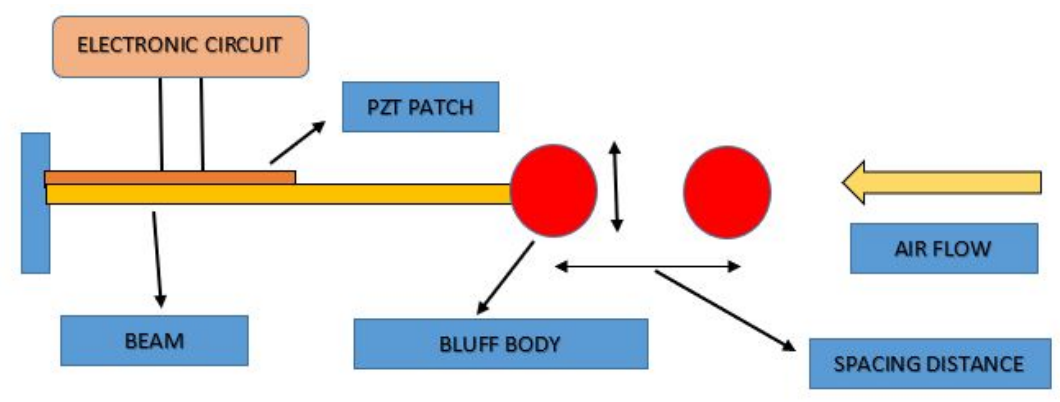

Figure 12. Wake galloping-based PEH schematic. Two bluff bodies are subjected to airflow. One is attached at the end of an elastic cantilever beam and another bluff body is placed in front of it.

An analytical model was developed for a triangular shaped bluff for galloping-based PEH. The effects of inductance, load resistance, and wind speed on the Hopf bifurctaion of the system were analyzed. Galloping arises when the electrical damping corresponding to Hopf bifurcation (EDHB) is greater than the electrical damping of the system. The EDHB has a positive linear relationship to the wind speed. So, in order to achieve galloping, wind speed should increase [123].Tan and Yan developed a theoretical model of galloping-based PEH to analyze the intrinsic effect of inductance and the electrical load resistance on the performance of a cantilever PEH. The average output obtained by this model is given by Equation (7) [166]:

$$
P_{\text {opt. }}^{\text {avg. }}=\frac{(A-2 \zeta \omega)^{2}}{-6 B},
$$

where $P_{\text {opt. }}^{a v g}$ is the average output of galloping-based PEH, $\zeta$ is the damping ratio, $\omega$ is the the first natural frequency of the cantilever beam, $A$ is the aerodynamic damping, and $B$ is the cubic nonlinear coefficient due to galloping.

To characterize the performance of PEH excited by galloping, experimentation was carried out in a wind tunnel for the comparison of harvested voltage and LCOs. For this purpose, bluff bodies of identical geometry and weight were analyzed. It was observed that the optimal bluff body had a wavelength of 2.5 , wave-steepness of 0.1 , and amplitude of 0.25 . The PEH could harvest energy up to $18 \%$ lower wind velocity, but the maximum voltage reduced to $7 \%$ [167]. This experimental setup is shown in Figure 13. 


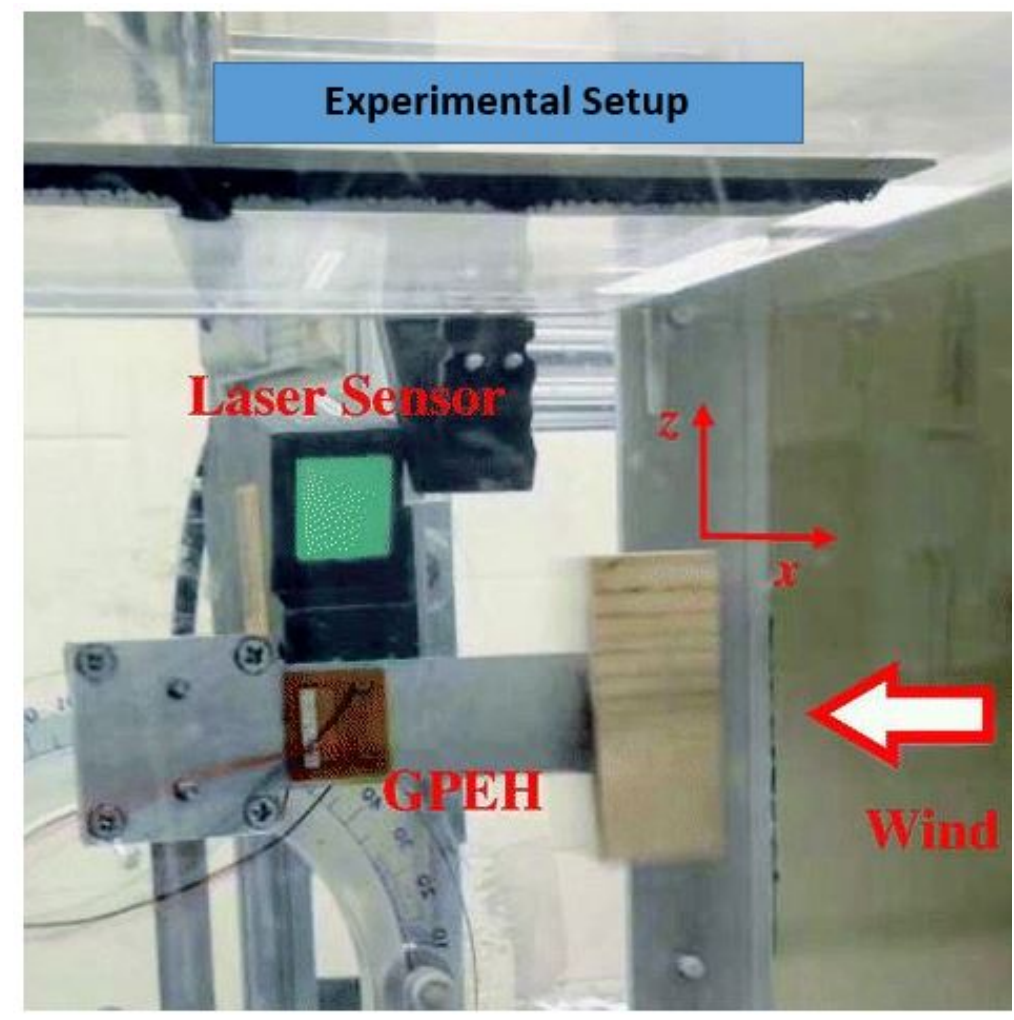

Figure 13. Galloping-based PEH (GPEH) in a test section of a subsonic wind tunnel [167].

Yan and Lei proposed a model for PEH that was excited by galloping but with a different $\mathrm{AC}$ and DC interface. They investigated the maximum output power by adjusting the optimal electrical load resistance in order to attain optimal/maximum electrical damping [168]. Petrini and Gkoumas analytically and experimentally investigated a PEH excited by galloping inside HVAC ducts. The device was excited by the airflow due to heating, ventilation, and air conditioning. The estimated power obtained from experimentation in a wind tunnel ranged from $3 \times 10^{-5}$ to $3 \times 10^{-7} \mathrm{~W}$ [155]. The design steps are expressed in Figure 14.

Table 2. Comparison of various FSI-based PEHs.

\begin{tabular}{cccccc}
\hline Mechanism & Design & PZT Type & Layer(s) & Power $(\mathbf{m W})$ & Reference \\
\hline VIV & Circular & PZT & 1 & 23 & {$[169]$} \\
VIV & Circular & PVDF & 1 & 0.004 & {$[170]$} \\
VIV & Circular & PZT-5A & 2 & 0.1 & {$[171]$} \\
Flutter & NACA0014 & PZT & 1 & 0.003 & {$[122]$} \\
Flutter & Typical section & PZT-5A4E & 1 & 0.0005 & {$[149]$} \\
Flutter & Symmetric & PSI-5A4E & 1 & 0.2 & {$[172]$} \\
Flutter & NACA 0012 & QP 10N & 2 & 2.2 & {$[173]$} \\
Galloping & Triangle & PZT & 2 & 3.8 & {$[123]$} \\
Galloping & Equilateral & PSI-5H4E & 4 & 50 & {$[174]$} \\
Galloping & Square & P-876.A12 & 2 & 8.4 & {$[175]$} \\
Galloping & Square & MFC-M8514-P2 & 1 & 0.22 & {$[176]$} \\
\hline
\end{tabular}




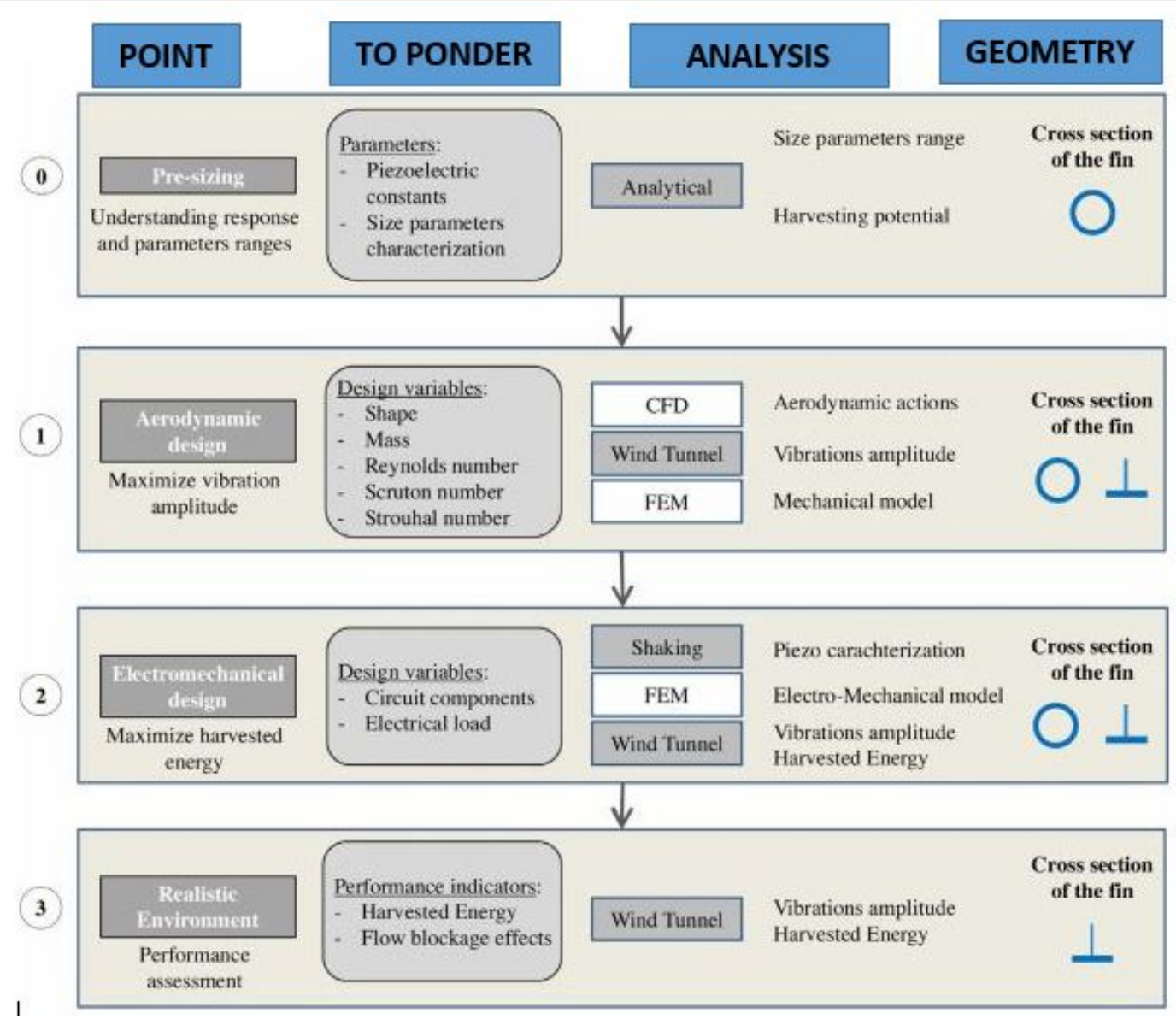

Figure 14. Design steps for PEH [155].

\subsection{Other Mechanisms for FSI-Based PEH}

The generation of energy under water by using a piezoaeroelastic energy harvester based on a heavy flag was developed by Giacomello and Porfiri. They obtained outputs on the order of $10^{-10} \mathrm{~W}$, which is not useful for most electronic devices [177]. Optimization of this design by playing with the Re of the fluid has been done by Aramendia et al., obtaining energy generation up to $0.9 \mathrm{~mW}$ for $\operatorname{Re}=12,000$ [178]. Flapping-leaf or flag-shaped piezoaeroelastic energy harvesters are of great interest for many researchers. Dunnmon et al. presented an experimental model of a flexible cantilever beam with piezoelectric lamination over it that is subjected to airflow. The harvested power was almost $2.5 \mathrm{~mW}$ for a $21 \mathrm{~m} / \mathrm{s}$ critical speed [179]. A further improvement was achieved by Li et al. by making an L-shape aeroelastic harvester using PVDF to oscillate at fluttering frequencies [180,181]. A further improvement was done by Kwon et al. by making a T-shape aeroelastic harvester using a bimorph piezoelectric cantilever beam [182]. It was capable of generating $4 \mathrm{~mW}$ of energy at a speed of $4 \mathrm{~m} / \mathrm{s}$.

Other mechanisms for FSI-based piezoelectric energy harvesters are explained in Table 3. 
Table 3. Other mechanisms for FSI-based PEHs. Re: Reynolds number.

\begin{tabular}{|c|c|}
\hline Description & References \\
\hline $\begin{array}{l}\text { Optimized underwater piezoelectric energy harvester that } \\
\text { can generate } 0.9 \mathrm{~mW} \text { of power for } \operatorname{Re}=12,000 .\end{array}$ & [178] \\
\hline $\begin{array}{l}\text { Underwater aeroealstic energy harvester from a heavy flag } \\
\text { that can generate power on the order of } 10^{-10} \mathrm{~W} \text { at } 0.6-1.1 \mathrm{~ms}^{-1} \text { fluid flow. }\end{array}$ & [177] \\
\hline $\begin{array}{l}\text { Piezoelectric wind energy harvester circuit proposed to destroy } \\
\text { the harmonics and increase the battery charge performance. }\end{array}$ & [70] \\
\hline $\begin{array}{l}\text { A cantilever beam with PZT laminate subjected to axial flow in a manner similar to a flapping } \\
\text { leaf or flag. The system accessed } 17 \% \text { of the energy to which it was exposed. } \\
\text { Output power RMS value was obtained to be maximum of } 2.5 \mathrm{~mW} \text { at } \approx 27 \mathrm{~ms}^{-1} \text { of flow. }\end{array}$ & [179] \\
\hline $\begin{array}{l}\text { Aeroelastic vibrations-based PVDF flapping flag } \\
\text { which can oscillate at wide fluttering frequency. }\end{array}$ & [180] \\
\hline Predicted vortex shedding from bluff body is the dominant exciter of oscillations. & {$[183,184]$} \\
\hline $\begin{array}{l}\text { The bluff body effect is ignored in the leading edge and } \\
\text { more importance is given to self-induced vibrations at the trailing edge. } \\
\text { This generator results in } 615 \mu \mathrm{W} \text { power harvesting at }<8 \mathrm{~ms}^{-1} \text { of flow }\end{array}$ & [181] \\
\hline $\begin{array}{l}\text { T-shaped piezoelectric harvester for aeroelastic flutter. } \\
\text { It can generate at } 4 \mathrm{~mW} \text { at } 4 \mathrm{~ms}^{-1} \text { of flow }\end{array}$ & [182] \\
\hline $\begin{array}{l}\text { Piezoelectric energy harvester based on turbulence-induced vibrations. It can generate } \\
1 \mathrm{~mW} \text { for a wind speed of } 11 \mathrm{~ms}^{-1} \text { for PZT and } 1 \mu \mathrm{W} \text { for a wind speed of } 7 \mathrm{~ms}^{-1} \text {. }\end{array}$ & {$[185,186]$} \\
\hline $\begin{array}{l}\text { Three piezoelectric patches are attached to harvest energy from the wing of an aircraft. } \\
\text { It can generate } 10.1-24 \mu \mathrm{W} \text { of power at a wind speed of } 11-25 \mathrm{kmh}^{-1} \text {. }\end{array}$ & [187] \\
\hline Tree-shaped harvester to generate a power of $2.24 \mathrm{~mW}$ from the wind speed of an electric fan. & [188] \\
\hline A piezoelectric windmill to generate power of $7.5 \mathrm{~mW}$ from a wind speed of $10 \mathrm{mph}$. & [189] \\
\hline
\end{tabular}

\section{Human-Based PEH}

In the past several decades, generating energy from the motion of humans [190-192], animals [193-195] and plants $[196,197]$ has been of great interest for many researchers. Due to the development of this technology, the charging of mobile micro or nanoelectronics is of great ease [198,199]. There are three mechanisms of harvesting energy from biomechanics: PZT [200-202], electromagnetic [203], and triboelectric [204]. In this section, only biomechanical-based PEHs are discussed. Energy that can be harvested from PZT patches from the movement of different human organs are expressed in Figure 15, and are elaborated in Table 4.

Table 4. Biomechanic-based PEH.

\begin{tabular}{cccc}
\hline Mechanism & PZT Type & Power $(\mathbf{m W})$ & References \\
\hline Center of Gravity & PVDF & 9.1 & {$[205]$} \\
Center of Gravity & PZT & 0.15 & {$[206]$} \\
Foot Strike & PZT & $8.4,90.3,0.35$ & {$[207-209]$} \\
Foot Strike & PVDF & $0.013,1,0.5$ & {$[210-212]$} \\
Knee & PZT & $3.5,5.8$ & {$[213,214]$} \\
Heel & PVDF & 120 & {$[215]$} \\
Jaw Movement & PVDF & 0.0174 & {$[216]$} \\
\hline
\end{tabular}




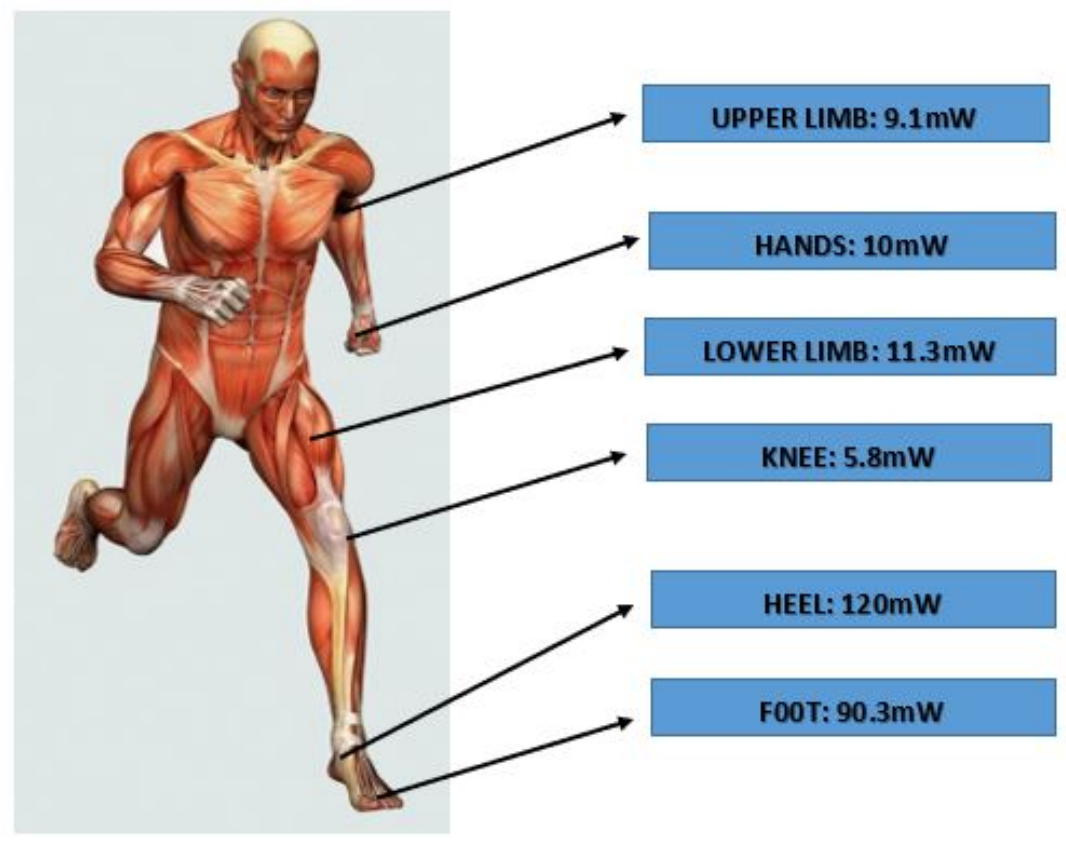

Figure 15. Piezoelectric energy harvesting from the human body.

The joints of the human body are in a continuous state of motion in a fixed axis, providing an excellent opportunity to harvest energy utilizing this motion as an input mechanical source $[217,218]$. The human body is capable of generating 2-20 W of power from foot strike, $66.8 \mathrm{~W}$ from ankle movement, $36.4 \mathrm{~W}$ from knee movement, $38 \mathrm{~W}$ from hip movement, $2.1 \mathrm{~W}$ from elbow movement, $2.2 \mathrm{~W}$ from shoulder movement, and $20 \mathrm{~W}$ from the center of gravity [217,219-221]. The energy that can be harvested from a human-based PZT harvester is given by Equation (8) [221]:

$$
E=\Delta P_{M} * \eta_{\text {Muscle }} * \eta_{\text {Device }}
$$

where $E$ is the electrical energy generated, $\Delta P_{M}$ is the change in metabolic power, $\eta_{\text {Muscle }}$ is the efficiency of muscles related to energy conversion for a given motion, and $\eta_{\text {Device }}$ is the efficiency of the device.

Renaud analyzed the parameters that can influence PEH for human limb. Experimentation was done on a prototype of $25 \mathrm{~cm}^{3}$ and $60 \mathrm{~g}$ in weight. Forty-seven $\mu \mathrm{W}$ of energy was generated with $180^{\circ}$ phase change, $600 \mu \mathrm{W} \mathrm{cm}{ }^{-3}$ were generated for the $10 \mathrm{~Hz}$ of frequency, and were further optimized to $120 \mu \mathrm{W}$ [222]. Siddiqui demonstrated the usage of 3D micro printed omni-directional substrates that are very flexible and robust even for the stretching of the knee. An output power of $1.76 \mu \mathrm{W} \mathrm{cm}{ }^{-2}$ was obtained from knee movements during a walk [4]. Kim analyzed the effect of force (4N) and frequency $(2 \mathrm{~Hz})$ on output power for human-based piezoelectric energy harvesters at different angles (i.e., $0^{\circ}$, $45^{\circ}$, and $90^{\circ}$ ). The output maximum power obtained was $0.064,0.026$, and $0.02 \mu \mathrm{W}$, respectively [192]. Bai performed experimentation and numerical solution to harvest energy from a piezoelectric wrist band; output RMS power obtained from movement of human wrist was $50 \mu \mathrm{W}$ [223]. Fan proposed a nonlinear PEH mounted on a shoe to generate voltage from human walking consisting of a PZT elastic cantilever beam that is magnetically linked to a ferromagnetic ball and cross beam; $0.035-0.35$ $\mathrm{mW}$ of output power could be obtained while walking from $2 \mathrm{~km} / \mathrm{h}$ to $8 \mathrm{~km} / \mathrm{h}$ [209]. The design of a glove having piezoelectric patches was proposed that can harvest energy because of flexion motion in fingers of the hand; $50 \mathrm{~V}$ could be generated from this mechanism, and could be utilized to drive a heat coil in a glove in order to provide thermal heating [224]. Halim and Park presented a model for PEH based on human limb motion as shown in Figure 16. The model consisted of two mass-loaded unimorph piezoelectric beams clamped on two flexible sidewalls that can be driven from low frequency. 
Each unimorph piezoelectric beam was able to generate power of $96 \mu \mathrm{W}$ at optimum load conditions and a frequency of $4.96 \mathrm{~Hz}$ [225].

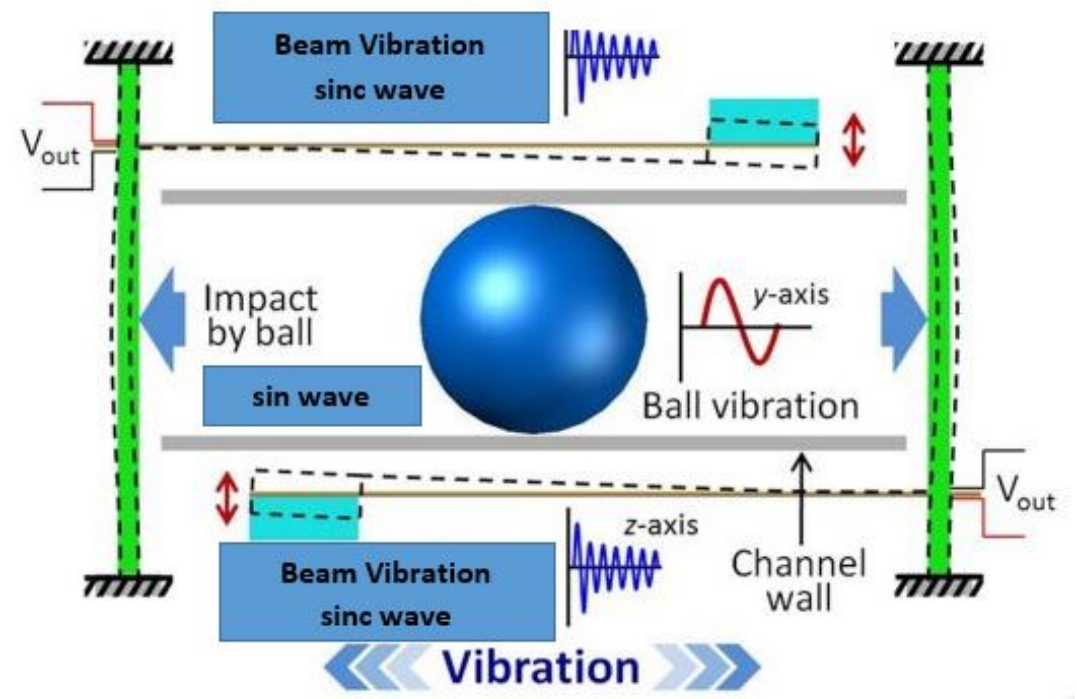

Figure 16. Schematic model of human limb-based PEH [225].

Researchers have shown great interest in biomechanics-based PEH, especially for pacemakers (Figure 17). From the relaxation and expansion motion of the heart, the PZT nanogenerator can generate electrical energy and it can be stored inside a specifically designed battery in the pacemaker [226]; $3 \mathrm{mV}$ of voltage could be generated from this mechanism for an adult. Ansari and Karami performed experimentation on PEH for pacemakers; a $1 \mathrm{~cm}^{3}$ PEH could generate $16 \mu \mathrm{W}$ of power from a normal human heart beat with a fan-folded structure consisting of a bimorph piezoelectric beam [227].

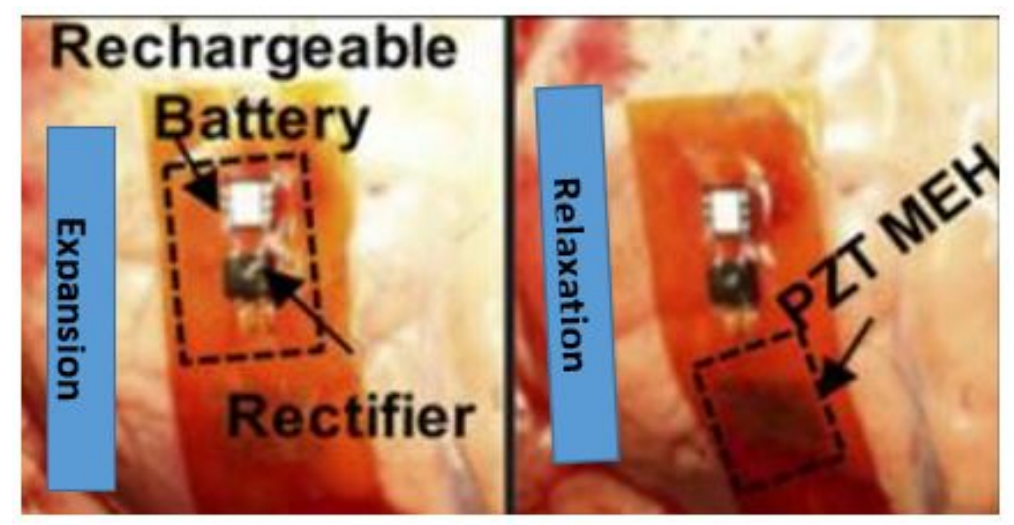

Figure 17. $\mathrm{PEH}$ for pacemaker. Expansion and relaxation of the pacemaker for the generation of voltage [226].

\section{Mechanical Vibrations-Based PEH}

Energy harvesting is driven by mechanical vibrations that result in the deformation of the host structures. These vibrations are transformed to piezoelectric patches for energy conversion [228]. In this section, continuous sources of mechanical vibrations at a few frequencies are studied considering their energy harvesting mechanism. For mechanical vibration-based energy harvesting, two phenomena are involved: structural resonance $[229,230]$ and local resonance [231]. In this section, the structural resonance-based harvesters are studied and a brief introduction to local resonance is incorporated. 


\subsection{Structural Resonance}

In this mechanism, the whole host structure undergoes a resonance behavior for harvesting energy via PZT [232]. This phenomenon can make use of a cantilever beam harvester mechanism or a plate-type harvester mechanism [228].

\subsubsection{Cantilever Beam Harvester Mechanism}

This mechanism is considered as the most efficient phenomenon, as energy is harvested from the resonance of the entire host cantilever beam [228]. The overall schematic of this mechanism is expressed in Figure 18, where either of layer 1 or layer 2 is a piezoelectric layer and the other is non-piezoelectric layer. These two layers are attached to each other by bonding, and the piezoelectric layer is shocked electrically at the desired resistance via external circuitry [10]. The number of PZT harvesters may vary according to the application (i.e., unimorph PZT configuration [233] and bimorph PZT configuration [234]). A quantitative analysis (summary) of various cantilever beam mechanism-based piezoelectric energy harvesting schemes is expressed in Table 5.

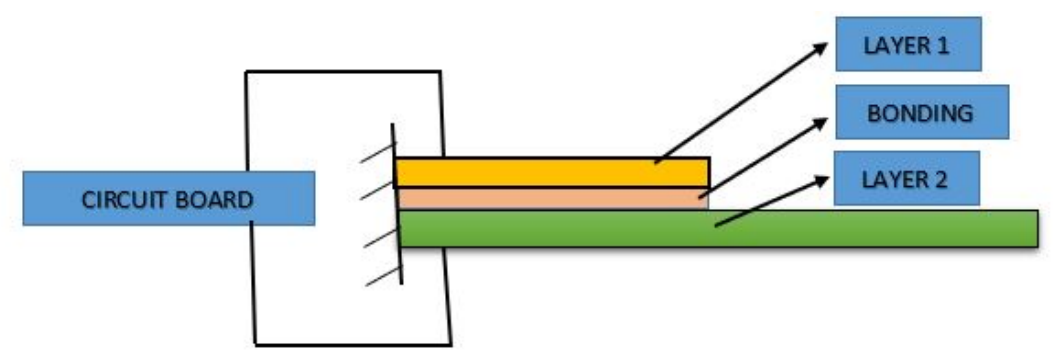

Figure 18. Cantilever beam mechanism-based piezoelectric energy harvesting schematic. 
Table 5. Comparison of various cantilever-based PEHs.

\begin{tabular}{|c|c|c|c|c|}
\hline Mechanism & Frequency $(\mathrm{Hz})$ & Electrical Load $(\mathrm{k} \Omega)$ & Power $(\mathrm{mW})$ & References \\
\hline Cantilever-type magnetic non-contact PEH & 32.56 & $0-200$ & 1.23 & [235] \\
\hline PZT cantilever beam energy harvester for wireless sensors in a satellite at variable temperature & $10-10,000$ & $0-100$ & 0.87 & {$[10]$} \\
\hline $\mathrm{BaTiO}_{3}$ cantilever beam energy harvester for aerospace applications & $10-10,000$ & $0-100$ & 0.064 & [64] \\
\hline PZT-5A4E beam energy harvester for cyclic loading & $10-100$ & $0-100$ & 0.32 & {$[28]$} \\
\hline PZT beam with tungsten mass at fixed end & 26.2 & 26 & 0.002 & {$[236]$} \\
\hline M-shaped PZT harvester & $4-8$ & 300 & 1 & [237] \\
\hline Microfabricated PZT radioisotope generator & 38 & 90 & 0.0013 & [238] \\
\hline PZT unimorph cantilever & 90 & - & 0.0057 & [239] \\
\hline Two PZT layers with opposite polarization & 100 & 9.9 & 0.0163 & [240] \\
\hline Bimorph PZT harvester with mass on free end & 120 & $\approx 300$ & 0.375 & {$[241,242]$} \\
\hline Sandwiched PZT cantilever beam & 125 & - & 0.03 & [243] \\
\hline PZT bimorph with mass at center & $200-250$ & 173 & $0.3-0.4$ & [244] \\
\hline Asymmetric air-spaced PZT energy harvester & $200-250$ & 173 & $0.3-0.4$ & [245] \\
\hline Improved power array-based PZT energy harvester & $\approx 230$ & - & 0.00398 & [245] \\
\hline PZT laminated energy harvester & $\approx 3000$ & 68 & 0.66 & [246] \\
\hline PZT energy harvester that can resonate at vibration of specific frequency & 13,970 & 5200 & 0.001 & [247] \\
\hline
\end{tabular}




\subsubsection{Plate-Type Harvester Mechanism}

Few researchers have emphasized the importance of plate-type PZT harvesters [228]. A schematic of an embedded-based PZT harvester is shown in Figure 19 [248], and a simple plate type-based PEH is shown in Figure 20 [249]. Recent developments in the field of plate-type PEHs are expressed in Table 6.

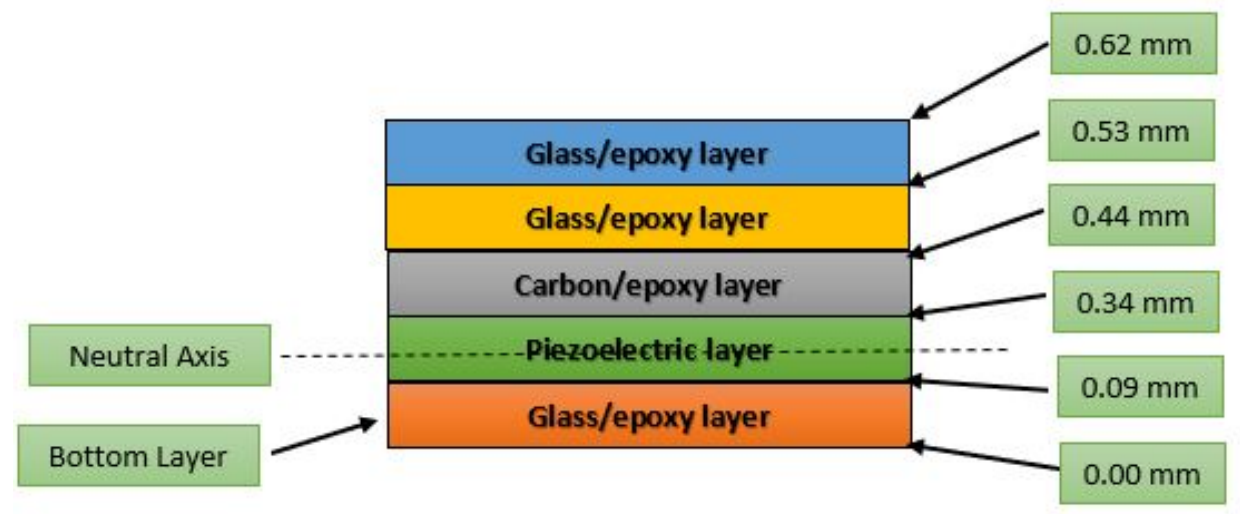

Figure 19. Plate-type mechanism-based embedded PEH schematic.

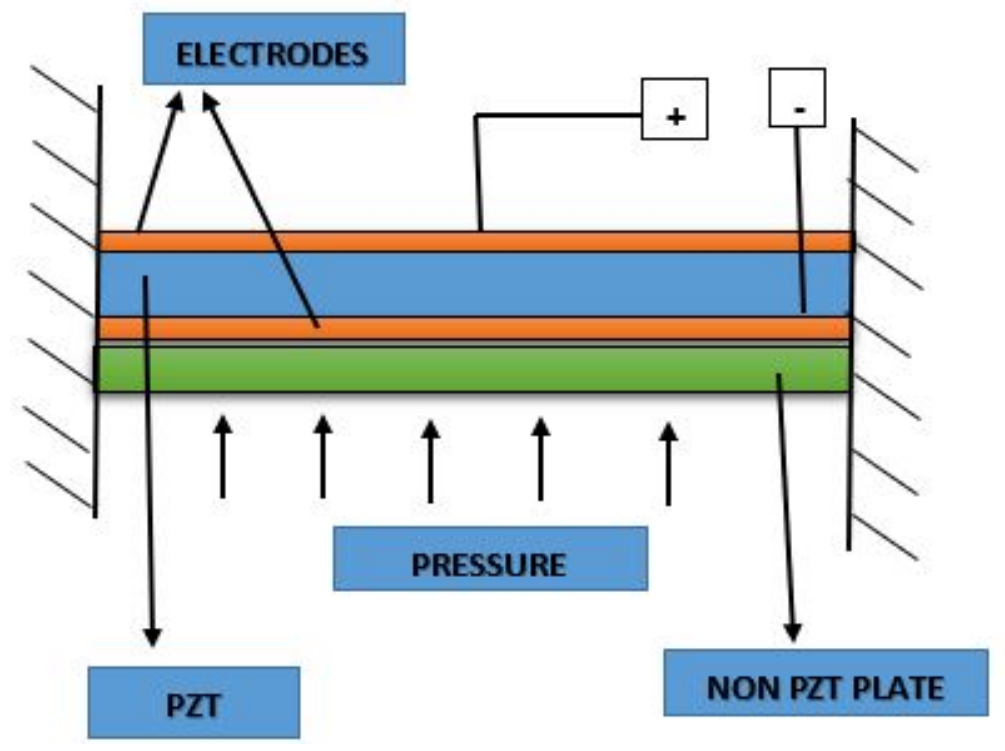

Figure 20. Plate-type mechanism-based PEH schematic. 
Table 6. Comparison of various cantilever-based PEHs.

\begin{tabular}{|c|c|c|c|c|}
\hline Mechanism & Frequency $(\mathrm{Hz})$ & Electrical Load $(\mathrm{k} \Omega)$ & Power $(\mathrm{mW})$ & Reference \\
\hline Bi-stable composite PZT plate for broadband energy harvesting & 38 & - & 36.2 & [250] \\
\hline PZT energy harvester for pavements & 10,15 & 20,10 & $0.88,11.67$ & [251] \\
\hline Simply supported plate type PZT layered harvester & $\approx 3000-20,000$ & $0.1-20$ & $\approx 0.0008-0.125$ & [248] \\
\hline Multi-layered harvester with PZT, carbon/epoxy and glass/epoxy layers & $212-310$ & 23 & $0.22-0.28$ & [248] \\
\hline Micropower harvester for gloves & $\approx 60$ & $\approx 1000$ & 0.011 & [252] \\
\hline PZT nanofibers for nanogenerator in soft polymers & $\approx 35$ & 6000 & 0.00003 & [253] \\
\hline
\end{tabular}




\subsection{Local Resonance}

In the last few decades, many materials have been synthesized artificially in order to harvest electrical energy, which are known as metamaterials. These materials are capable of harvesting energy using the phenomenon of local resonance. In metamaterials, a piezoelectric material is placed close to a local resonating point to get maximum energy harvesting [228]. These materials have vast applications in complicated integrated circuits in various electronic devices.

PCs use various types of band filters to filter out waves known as the band gap. These frequencies can be utilized to resonate a localized smart material inside a structure, which is an ideal condition to harvest energy [254]. Carrera et al. performed an experimental campaign under various conditions (Figure 21), and concluded that PC-based harvesters are more efficient as compared to others. Just like PCs, SCs are also used as energy harvesters because of their ability to block or filter out specific frequencies. Unlike PCs, however, SCs use soft material as host to house the resonator [255]. Zhang et al. designed a square-shape SC that is capable of generating power on the order of $\mathrm{nW}$. Thesquare mass is surrounded by four square convolute beams, as shown in Figure 22.

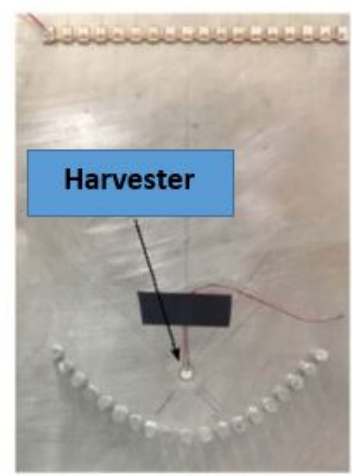

(a)

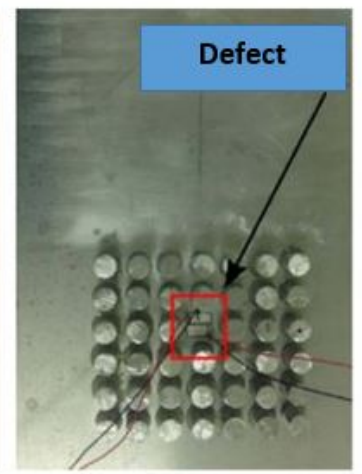

(b)

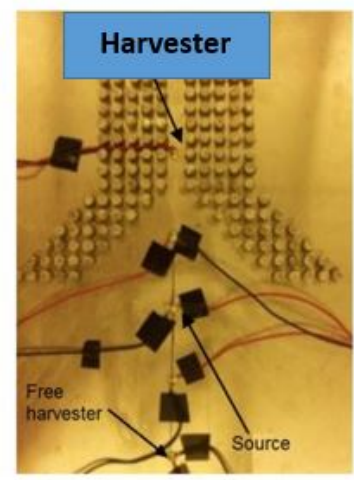

(c)

Figure 21. PEH configurations: (a) parabolic acoustic mirror; (b) point defect; and (c) acoustic funnel [256].

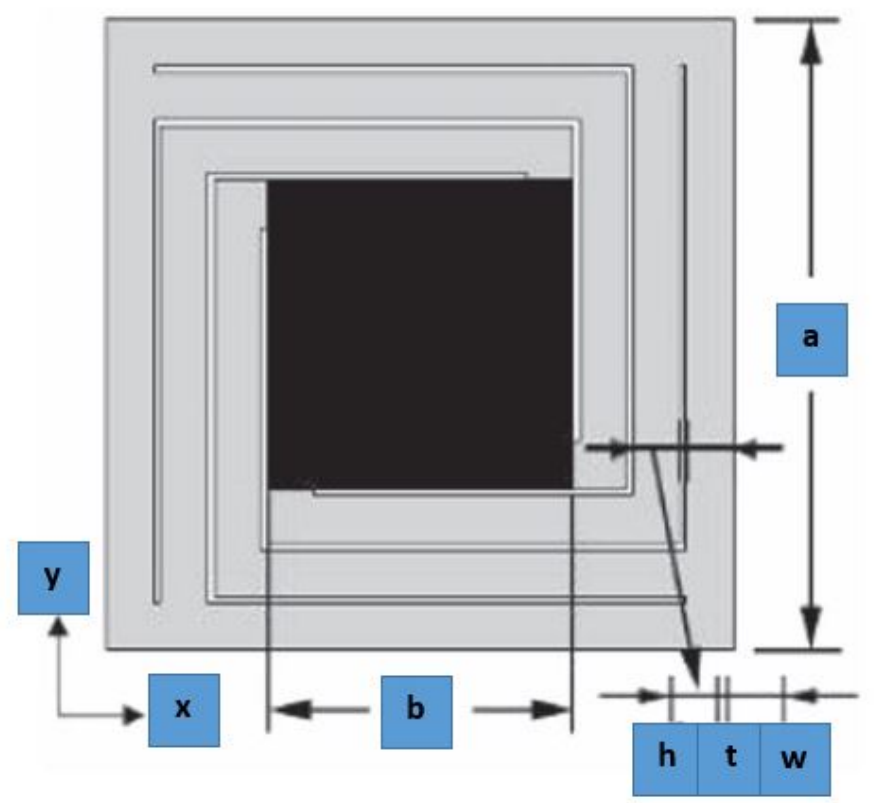

Figure 22. Unit cell in the proposed locally resonant structure [255]. 


\title{
5. Concluding Remarks
}

In this review paper, mechanisms of piezoelectric energy harvesting based on fluid-structure interaction, human movement, and vibration are studied. Quantitative as well as qualitative analysis of the existing state-of-the-art literature was carried out. Piezoelectric materials are highlighted as an alternate source of energy for defence industries.

The lifespan of batteries is unpredictable, and in many cases their replacement or maintenance is impossible. Furthermore, battery terminals can be destroyed quickly, as it is charged by the micro or nano Watt extracted by PEH. Thirdly, if batteries (i.e., lead ion battery) are not dumped properly, they can be environmental hazards. So, there is a vast scope of PEH to replace batteries or to improve the lifespan of batteries by reducing the charging time, and the design of battery terminals can be improved so that they may not be affected by low voltage input. In harsh conditions such as hot weather, the battery life reduces, whereas the efficiency of PEH is improved in hot weather.

Significant research has been done on aeroelastic energy harvesters, but aerodynamic models can be improved by taking into account the difference and comparison of steady, quasi-steady, and unsteady aerodynamics. No significant experimentation has been done on underwater-based $\mathrm{PEH}$, which can be utilized to drive wireless sensors in submarines or ships. As the energy generated from FSI is on the order of micro or nano watts, it is recommended to construct a model with multiple flexible piezoelectric patches in order to improve efficiency.

As the world is shifting towards nano-electronics, human-based PEH can play a vital role in charging mobile electronic devices (i.e., cellular phones, laptop batteries, etc.). Because human joints/organs are in almost-continuous motion, this PEH modality may prove to be very efficient. Harvesters for human joints (e.g., elbow, wrist) are recommended. It can also be proposed to have a laptop keyboard or the keypad of a cellular phone with piezoelectric patches, allowing batteries to be charged while the users type.

In order to harvest high energy from $\mathrm{PEH}$, it is recommended to use piezoelectric materials with a higher coupling coefficient. There is a vacuum for material engineers to develop doped piezoelectric patches with higher coupling coefficients. Specialized amplifiers can also be utilized in order to amplify the output voltage generated by piezoelectric materials. The efficiency of vibration-based PEH can be improved by optimizing the geometry of the system and locating the piezoelectric patch close to the resonating point so that maximum mechanical energy can be absorbed by the $\mathrm{PEH}$ and converted to useful electrical energy.

Author Contributions: All the authors contributed equally for literature survey, discussions, and review of the paper.

Conflicts of Interest: The authors declare no conflict of interest.The founding sponsors had no role in the design of the study; in the collection, analyses, or interpretation of data; in the writing of the manuscript, and in the decision to publish the results.

\author{
Abbreviations \\ The following abbreviations are used in this manuscript: \\ $\alpha \quad$ pitch angle \\ $\Delta P_{M} \quad$ change in metabolic power \\ $\epsilon_{k} \quad$ strain vector \\ $\eta_{\text {Device }} \quad$ efficiency of device \\ $\eta_{\text {Muscle }}$ efficiency of muscles related to energy conversion for a given motion \\ $\sigma_{m} \quad$ stress vector \\ $\theta \quad$ angular displacement \\ $b \quad$ half chord length \\ $c_{\alpha} \quad$ pitch structural damping coefficient \\ $c_{h} \quad$ plunge structural damping coefficient \\ $C_{p} \quad$ capacitance of the piezoelectric layer
}




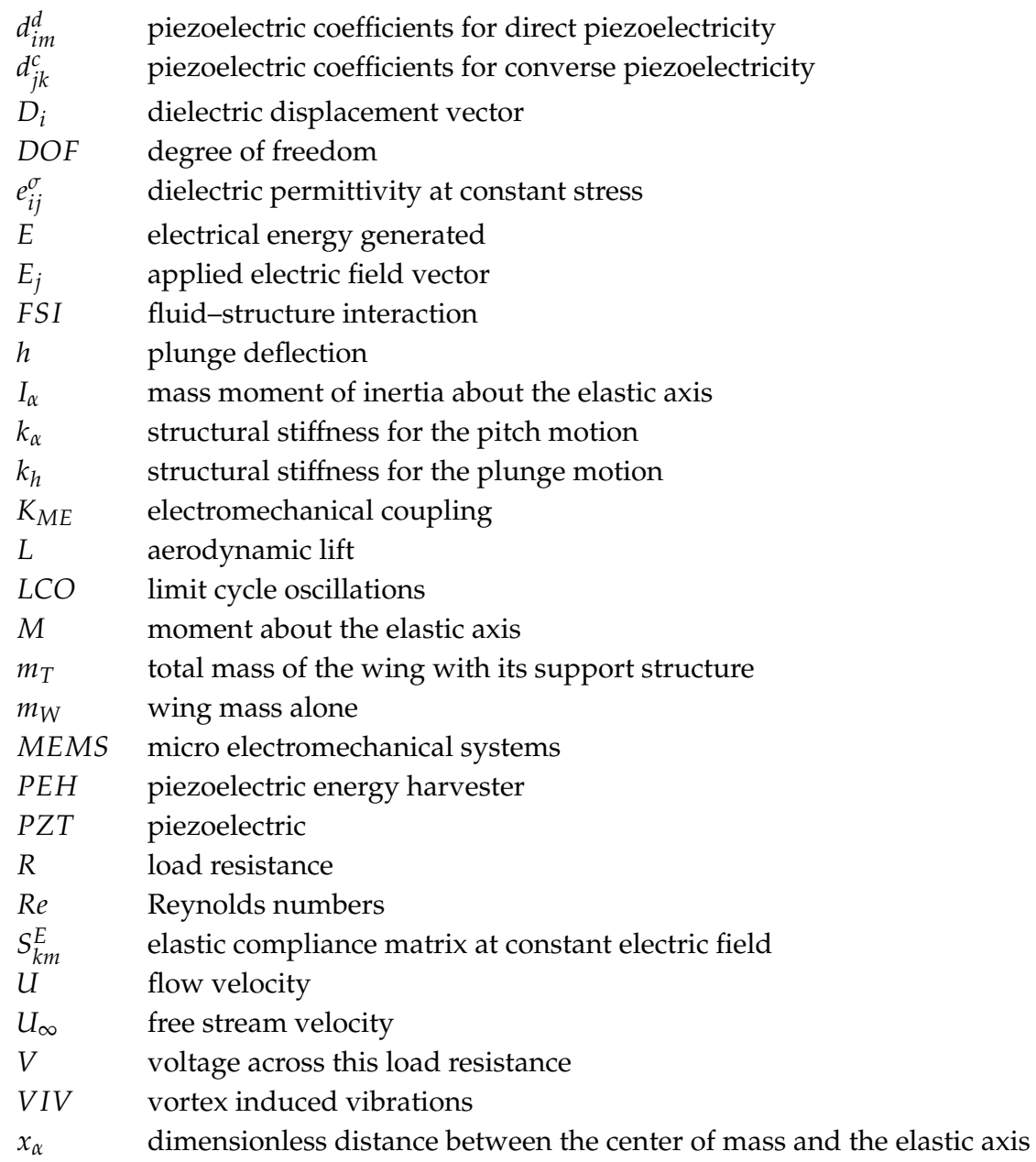

\section{References and Notes}

1. Gaudenzi, P. Smart Structures: Physical Behaviour, Mathematical Modelling and Applications; John Wiley \& Sons: Hoboken, NJ, USA, 2009.

2. Srinivasan, A.V.; McFarland, D.M. Smart Structures: Analysis and Design; Cambridge University Press: Cambridge, UK, 2001.

3. Martinez, T.; Pillonnet, G.; Costa, F. A 15-mV Inductor-Less Start-up Converter Using a Piezoelectric Transformer for Energy Harvesting Applications. IEEE Trans. Power Electron. 2018, 33, 2241-2253. [CrossRef]

4. Siddiqui, S.; Lee, H.B.; Kim, D.I.; Duy, L.T.; Hanif, A.; Lee, N.E. An Omnidirectionally Stretchable Piezoelectric Nanogenerator Based on Hybrid Nanofibers and Carbon Electrodes for Multimodal Straining and Human Kinematics Energy Harvesting. Adv. Energy Mater. 2018, 8, 1701520. [CrossRef]

5. Xu, S.; Shi, Y.; Kim, S.G. Fabrication and mechanical property of nano piezoelectric fibres. Nanotechnology 2006, 17, 4497. [CrossRef]

6. Zhao, T.; Fu, Y.; He, H.; Dong, C.; Zhang, L.; Zeng, H.; Xing, L.; Xue, X. Self-powered gustation electronic skin for mimicking taste buds based on piezoelectric-enzymatic reaction coupling process. Nanotechnology 2018, 29, 075501. [CrossRef] [PubMed]

7. Jin, W.; Wang, Z.; Huang, H.; Hu, X.; He, Y.; Li, M.; Li, L.; Gao, Y.; Hu, Y.; Gu, H. High-performance piezoelectric energy harvesting of vertically aligned $\mathrm{Pb}(\mathrm{Zr}, \mathrm{Ti}) \mathrm{O}_{3}$ nanorod arrays. RSC Adv. 2018, 8, 7422-7427. [CrossRef]

8. Anton, S.R.; Sodano, H.A. A review of power harvesting using piezoelectric materials (2003-2006). Smart Mater. Struct. 2007, 16, R1. [CrossRef]

9. Kim, H.S.; Kim, J.H.; Kim, J. A review of piezoelectric energy harvesting based on vibration. Int. J. Precis. Eng. Manuf. 2011, 12, 1129-1141. [CrossRef] 
10. Elahi, H.; Butt, Z.; Eugnei, M.; Gaudenzi, P.; Israr, A. Effects of variable resistance on smart structures of cubic reconnaissance satellites in various thermal and frequency shocking conditions. J. Mech. Sci. Technol. 2017, 31, 4151-4157. [CrossRef]

11. Song, H.C.; Kumar, P.; Maurya, D.; Kang, M.G.; Reynolds, W.T.; Jeong, D.Y.; Kang, C.Y.; Priya, S. Ultra-Low Resonant Piezoelectric MEMS Energy Harvester with High Power Density. J. Microelectromech. Syst. 2017, 26, 1226-1234. [CrossRef]

12. Kudela, P.; Radzienski, M.; Ostachowicz, W.; Yang, Z. Structural Health Monitoring system based on a concept of Lamb wave focusing by the piezoelectric array. Mech. Syst. Signal Process. 2018, 108, 21-32. [CrossRef]

13. Zappino, E.; Carrera, E. Refined one-dimensional models for the multi-field analysis of layered smart structures. In Analysis and Modelling of Advanced Structures and Smart Systems; Springer: Berlin, Germnay, 2018; pp. 343-366.

14. Liu, L.; Pang, Y.; Yuan, W.; Zhu, Z.; Yang, Y. A self-powered piezoelectric energy harvesting interface circuit with efficiency-enhanced P-SSHI rectifier. J. Semiconduct. 2018, 39, 045002. [CrossRef]

15. Lozano, F.J.; Lozano, R. Assessing the potential sustainability benefits of agricultural residues: biomass conversion to syngas for energy generation or to chemicals production. J. Clean. Prod. 2018, 172, 4162-4169. [CrossRef]

16. Johnston, D.T.; Furness, R.W.; Robbins, A.M.; Tyler, G.; Taggart, M.A.; Masden, E.A. Black guillemot ecology in relation to tidal stream energy generation: An evaluation of current knowledge and information gaps. Mar. Environ. Res. 2018, 134, 121-129. [CrossRef] [PubMed]

17. Randolph, J.B. Carbon Dioxide-Based Geothermal Energy Generation Systems and Methods Related Thereto. US Patent 9,869,167, 16 January 2018.

18. Dos Santos, I.F.S.; Vieira, N.D.B.; de Nóbrega, L.G.B.; Barros, R.M.; Tiago Filho, G.L. Assessment of potential biogas production from multiple organic wastes in Brazil: Impact on energy generation, use, and emissions abatement. Resour. Conserv. Recycl. 2018, 131, 54-63. [CrossRef]

19. Dixit, A.; Kamboj, S. Design, Simulation and Optimization of Piezoelectric Nano-Structures for Energy Harvesting. 2015.

20. Zhang, Q.; Zhou, Z.; Dylla, M.; Agne, M.T.; Pei, Y.; Wang, L.; Tang, Y.; Liao, J.; Li, J.; Bai, S.; et al. Realizing high-performance thermoelectric power generation through grain boundary engineering of skutterudite-based nanocomposites. Nano Energy 2017, 41, 501-510. [CrossRef]

21. Hosenuzzaman, M.; Rahim, N.; Selvaraj, J.; Hasanuzzaman, M.; Malek, A.; Nahar, A. Global prospects, progress, policies, and environmental impact of solar photovoltaic power generation. Renew. Sustain. Energy Rev. 2015, 41, 284-297. [CrossRef]

22. Allan, G.; Eromenko, I.; Gilmartin, M.; Kockar, I.; McGregor, P. The economics of distributed energy generation: A literature review. Renew. Sustain. Energy Rev. 2015, 42, 543-556. [CrossRef]

23. Yuce, B.; Rezgui, Y.; Mourshed, M. ANN-GA smart appliance scheduling for optimised energy management in the domestic sector. Energy Build. 2016, 111, 311-325. [CrossRef]

24. Girotto, F.; Alibardi, L.; Cossu, R. Food waste generation and industrial uses: a review. Waste Manag. 2015, 45, 32-41. [CrossRef] [PubMed]

25. Kirby, M.A.; Ozaki, E.T.; Burdo, R.; Keating, V.W.; Mangan, M.J.; Konertz, A.K.; Jacobs, P.E.; Von Novak, W.; Quick, R.F., Jr.; Davis, R.H.; et al. Wireless Power and Data Transfer for Electronic Devices. US Patent 8,947,042, 3 February 2015.

26. Ueda, S.; Okada, M.; Nakaue, Y. Transient thermal response of a functionally graded piezoelectric laminate with a crack normal to the bimaterial interface. J. Therm. Stress. 2018, 41, 98-118. [CrossRef]

27. Anderson, M.; Zagrai, A.N.; Daniel, J.D.; Westpfahl, D.J.; Henneke, D. Investigating Effect of Space Radiation Environment on Piezoelectric Sensors: Cobalt-60 Irradiation Experiment. J. Nondestruct. Eval. Diagn. Progn. Eng. Syst. 2018, 1, 011007. [CrossRef]

28. Elahi, H.; Eugeni, M.; Gaudenzi, P. Electromechanical Degradation of Piezoelectric Patches. In Analysis and Modelling of Advanced Structures and Smart Systems; Springer: Berlin, Germnay, 2018; pp. 35-44.

29. Butt, Z.; Pasha, R.A.; Qayyum, F.; Anjum, Z.; Ahmad, N.; Elahi, H. Generation of electrical energy using lead zirconate titanate (PZT-5A) piezoelectric material: Analytical, numerical and experimental verifications. J. Mech. Sci. Technol. 2016, 30, 3553-3558. [CrossRef] 
30. Butt, Z.; Rahman, S.U.; Pasha, R.A.; Mehmood, S.; Abbas, S.; Elahi, H. Characterizing Barium Titanate Piezoelectric Material Using the Finite Element Method. Trans. Electr. Electron. Mater. 2017, 18, 163-168.

31. Xia, Y.; Michelin, S.; Doaré, O. Fluid-solid-electric lock-in of energy-harvesting piezoelectric flags. Phys. Rev. Appl. 2015, 3, 014009. [CrossRef]

32. Elahi, H.; Pasha, R.; Khan, M. Experimental determination of mechanical quality factor of lead zirconate titanate (PZT-5A4E) by equivalent circuit method under various thermal and resistance conditions. Univ. Eng. Technol. Taxila Tech. J. 2014, 19, 1.

33. Kim, M.; Dugundji, J.; Wardle, B.L. Efficiency of piezoelectric mechanical vibration energy harvesting. Smart Mater. Struct. 2015, 24, 055006. [CrossRef]

34. Yang, Z.; Erturk, A.; Zu, J. On the efficiency of piezoelectric energy harvesters. Extrem. Mech. Lett. 2017, 15, 26-37. [CrossRef]

35. Kudryavtsev, M.; Rudnyi, E.B.; Korvink, J.G.; Hohlfeld, D.; Bechtold, T. Computationally efficient and stable order reduction methods for a large-scale model of MEMS piezoelectric energy harvester. Microelectron. Reliab. 2015, 55, 747-757. [CrossRef]

36. Webster, J.G.; Eren, H. Measurement, Instrumentation, and Sensors Handbook: Spatial, Mechanical, Thermal, and Radiation Measurement; CRC Press: Boca Raton, FL, USA, 2017.

37. Edwards, B.; Hu, P.A.; Aw, K.C. Validation of a hybrid electromagnetic-piezoelectric vibration energy harvester. Smart Mater. Struct. 2016, 25, 055019. [CrossRef]

38. Siddique, A.R.M.; Mahmud, S.; Van Heyst, B. A comprehensive review on vibration based micro power generators using electromagnetic and piezoelectric transducer mechanisms. Energy Convers. Manag. 2015, 106, 728-747. [CrossRef]

39. Li, P.; Gao, S.; Cai, H. Modeling and analysis of hybrid piezoelectric and electromagnetic energy harvesting from random vibrations. Microsyst. Technol. 2015, 21, 401-414. [CrossRef]

40. Dagdeviren, C.; Joe, P.; Tuzman, O.L.; Park, K.I.; Lee, K.J.; Shi, Y.; Huang, Y.; Rogers, J.A. Recent progress in flexible and stretchable piezoelectric devices for mechanical energy harvesting, sensing and actuation. Extrem. Mech. Lett. 2016, 9, 269-281. [CrossRef]

41. Huang, Y. Packaging and Connecting Electrostatic Transducer Arrays. US Patent 8,815,653, 26 August 2014.

42. Dorzhiev, V.; Karami, A.; Basset, P.; Marty, F.; Dragunov, V.; Galayko, D. Electret-free micromachined silicon electrostatic vibration energy harvester with the Bennet's doubler as conditioning circuit. IEEE Electron Device Lett. 2015, 36, 183-185. [CrossRef]

43. Elahi, H.; Israr, A.; Swati, R.; Khan, H.; Tamoor, A. Stability of piezoelectric material for suspension applications. In Proceedings of the IEEE 2017 Fifth International Conference onAerospace Science and Engineering (ICASE), Islamabad, Pakistan, 14-16 November 2017; pp. 1-5.

44. Saoutieff, E.; Allain, M.; Nowicki-Bringuier, Y.R.; Viana, A.; Pauliac-Vaujour, E. Integration of piezoelectric nanowires matrix onto a microelectronics chip. Procedia Eng. 2016, 168, 1638-1641. [CrossRef]

45. Shaikh, F.K.; Zeadally, S. Energy harvesting in wireless sensor networks: A comprehensive review. Renew. Sustain. Energy Rev. 2016, 55, 1041-1054. [CrossRef]

46. Zhang, G. Piezoelectric Properties and Applications of PZT Nanofibers. Ph.D. Thesis, Stevens Institute of Technology, Hoboken, NJ, USA, 2015.

47. Kim, M.; Ito, R.; Kim, S.; Khanal, G.P.; Fujii, I.; Suzuki, T.S.; Uchikoshi, T.; Moriyoshi, C.; Kuroiwa, Y.; Wada, S. Fabrication of lead-free piezoelectric $\left(\mathrm{Bi}_{0.5} \mathrm{Na}_{0.5}\right) \mathrm{TiO}_{3}-\mathrm{BaTiO}_{3}$ ceramics using electrophoretic deposition. J. Mater. Sci. 2018, 53, 2396-2404. [CrossRef]

48. Woo, M.S.; Ahn, J.H.; Eom, J.H.; Hwang, W.S.; Kim, J.H.; Yang, C.H.; Song, G.J.; Do Hong, S.; Jhun, J.P.; Sung, T.H. Study on increasing output current of piezoelectric energy harvester by fabrication of multilayer thick film. Sens. Actuators A Phys. 2018, 269, 524-534. [CrossRef]

49. Yuan, T.C.; Yang, J.; Chen, L.Q. Nonlinear dynamics of a circular piezoelectric plate for vibratory energy harvesting. Commun. Nonlinear Sci. Numer. Simul. 2018, 59, 651-656. [CrossRef]

50. Li, J.; Li, Y.; Meng, Q.; Zhou, Z.; Jia, D.; McIntosh, R.; Bhalla, A.S.; Guo, R. Large electro-optic response of bulk ferroelectric crystals enhanced by piezoelectric resonance in the high frequency range. Mater. Res. Bull. 2018, 97, 523-529. [CrossRef]

51. Wang, G.; Liao, W.H.; Yang, B.; Wang, X.; Xu, W.; Li, X. Dynamic and energetic characteristics of a bistable piezoelectric vibration energy harvester with an elastic magnifier. Mech. Syst. Signal Process. 2018, 105, 427-446. [CrossRef] 
52. Katzir, S. The discovery of the piezoelectric effect. Arch. Hist. Exact Sci. 2003, 57, 61-91. [CrossRef]

53. Choi, B.K.; Lee, W.H. Study on the Energy Harvesting System Using Piezoelectric Direct Effect of Piezo Film. J. Korean Soc. Precis. Eng. 2008, 25, 78-85.

54. Zhu, R.; Yang, R. Introduction to the Piezotronic Effect and Sensing Applications. In Synthesis and Characterization of Piezotronic Materials for Application in Strain/Stress Sensing; Springer: Berlin, Germnay, 2018; pp. 1-4.

55. Jaffe, B. Piezoelectric Ceramics; Elsevier: NewYork, NY, USA, 2012; Volume 3.

56. Hehn, T.; Manoli, Y. Piezoelectricity and Energy Harvester Modelling. In CMOS Circuits for Piezoelectric Energy Harvesters; Springer: Berlin, Germnay, 2015; pp. 21-40.

57. Waqar, S.; Asad, S.; Ahmad, S.; Abbas, C.A.; Elahi, H. Effect of drilling parameters on hole quality of Ti-6Al-4V titanium alloy in dry drilling. In Materials Science Forum; Trans Tech Publications: Zurich, Switzerland, 2017; Volume 880, pp. 33-36.

58. Rehman, W.U.; Nawaz, H.; Wang, S.; Wang, X.; Luo, Y.; Yun, X.; Iqbal, M.N.; Zaheer, M.A.; Azhar, I.; Elahi, H. Trajectory based motion synchronization in a dissimilar redundant actuation system for a large civil aircraft. In Proceedings of the IEEE 2017 29th Chinese Control And Decision Conference (CCDC), Chongqing, China, 28-30 May 2017; pp. 5010-5015.

59. Rehman, W.U.; Yuanxin, L.; Guiyun, J.; Yongqin, W.; Yun, X.; Iqbal, M.N.; Zaheer, M.A.; Azhar, I.; Elahi, H.; Xiaogao, Y. Control of an oil film thickness in a hydrostatic journal bearing under different dynamic conditions. In Proceedings of the IEEE 2017 29th Chinese Control And Decision Conference (CCDC), Chongqing, China, 28-30 May 2017; pp. 5072-5076.

60. Elahi, H.; Israr, A.; Khan, M.Z.; Ahmad, S. Robust vehicle suspension system by converting active \& passive control of a vehicle to semi-active control system analytically. J. Autom. Control Eng. 2016, 4, 300-304.

61. Repp, S.; Harputlu, E.; Gurgen, S.; Castellano, M.; Kremer, N.; Pompe, N.; Wörner, J.; Hoffmann, A.; Thomann, R.; Emen, F.M.; et al. Synergetic effects of $\mathrm{Fe}^{3+}$ doped spinel $\mathrm{Li}_{4} \mathrm{Ti}_{5} \mathrm{O}_{12}$ nanoparticles on reduced graphene oxide for high surface electrode hybrid supercapacitors. Nanoscale 2018, 10, 1877-1884 . [CrossRef] [PubMed]

62. Genc, R.; Alas, M.O.; Harputlu, E.; Repp, S.; Kremer, N.; Castellano, M.; Colak, S.G.; Ocakoglu, K.; Erdem, E. High-capacitance hybrid supercapacitor based on multi-colored fluorescent carbon-dots. Sci. Rep. 2017, 7, 11222. [CrossRef] [PubMed]

63. Chopra, I. Review of state of art of smart structures and integrated systems. AIAA J. 2002, 40, $2145-2187$. [CrossRef]

64. Elahi, H.; Eugeni, M.; Gaudenzi, P.; Qayyum, F.; Swati, R.F.; Khan, H.M. Response of piezoelectric materials on thermomechanical shocking and electrical shocking for aerospace applications. Microsyst. Technol. 2018. [CrossRef]

65. Guillon, O.; Thiebaud, F.; Delobelle, P.; Perreux, D. Tensile behavior of PZT in short and open-circuit conditions. Mater. Lett. 2004, 58, 986-990. [CrossRef]

66. Xu, X.; Potié, A.; Songmuang, R.; Lee, J.W.; Bercu, B.; Baron, T.; Salem, B.; Montès, L. An improved AFM cross-sectional method for piezoelectric nanostructures properties investigation: application to GaN nanowires. Nanotechnology 2011, 22, 105704. [CrossRef] [PubMed]

67. Yang, J.; Zhang, F.; Yang, Q.; Liu, Z.; Li, Y.; Liu, Y.; Zhang, Q. Large piezoelectric properties in KNN-based lead-free single crystals grown by a seed-free solid-state crystal growth method. Appl. Phys. Lett. 2016, 108, 182904. [CrossRef]

68. Jung, J.P.; Lee, J.B.; Lee, M.H.; Park, J.S. Experimental and theoretical investigation on the relationship between AlN properties and AlN-based FBAR characteristics. In Proceedings of the 2003 IEEE International Frequency Control Symposium and PDA Exhibition Jointly with the 17th European Frequency and Time Forum, Tampa, FL, USA, 4-8 May 2003; pp. 779-784.

69. Paradiso, J.A.; Starner, T. Energy scavenging for mobile and wireless electronics. IEEE Pervasive Comput. 2005, 4, 18-27. [CrossRef]

70. Bouzelata, Y.; Kurt, E.; Uzun, Y.; Chenni, R. Mitigation of high harmonicity and design of a battery charger for a new piezoelectric wind energy harvester. Sens. Actuators A Phys. 2018, 273, 72-83. [CrossRef]

71. Li, Z.; Shan, J. LQG-based synchronization control of Fabry-Perot spectrometer using multiple piezoelectric actuators (PEAs). In Proceedings of the 2016 IEEE International Conference on Information and Automation (ICIA), Ningbo, China, 31 July-4 August 2016; pp. 448-453. 
72. Salim, M.; Salim, D.; Chandran, D.; Aljibori, H.S.; Kherbeet, A.S. Review of nano piezoelectric devices in biomedicine applications. J. Intell. Mater. Syst. Struct. 2018, 29, 2105-2121. [CrossRef]

73. Ai, D.; Zhu, H.; Luo, H.; Wang, C. Mechanical impedance based embedded piezoelectric transducer for reinforced concrete structural impact damage detection: A comparative study. Constr. Build. Mater. 2018, 165, 472-483. [CrossRef]

74. Pandey, R.; Khatua, D.K.; Tyagi, S.; Abebe, M.; Narayan, B.; Sathe, V.; Ranjan, R. Length-scale dependent average structures, piezoelectricity enhancement and depolarization mechanisms in a non-MPB high-performance piezoelectric alloy system $\mathrm{PbTiO}_{3}-\mathrm{Bi}(\mathrm{Zr} 1 / 2 \mathrm{Ni1} / 2) \mathrm{O}_{3}$. arXiv 2018, arXiv:1801.03310.

75. Erturk, A.; Delporte, G. Underwater thrust and power generation using flexible piezoelectric composites: an experimental investigation toward self-powered swimmer-sensor platforms. Smart Mater. Struct. 2011, 20, 125013. [CrossRef]

76. Muralt, P.; Marzencki, M.; Belgacem, B.; Calame, F.; Basrour, S. Vibration energy harvesting with PZT micro device. Procedia Chem. 2009, 1, 1191-1194. [CrossRef]

77. Sarker, M.R.; Ali, S.H.; Othman, M.; Islam, M.S. Designing a low voltage energy harvesting circuits for rectified storage voltage using vibrating piezoelectric. In Proceedings of the 2011 IEEE Student Conference on Research and Development (SCOReD), Cyberjaya, Malaysia, 19-20 December 2011; pp. 343-346.

78. Elahi, H.; Eugeni, M.; Gaudenzi, P.; Gul, M.; Swati, R.F. Piezoelectric thermo electromechanical energy harvester for reconnaissance satellite structure. Microsyst. Technol. 2018, 1-8. [CrossRef]

79. Muruganantham, B.; Gnanadass, R.; Padhy, N. Challenges with renewable energy sources and storage in practical distribution systems. Renew. Sustain. Energy Rev. 2017, 73, 125-134. [CrossRef]

80. Mann, B.; Sims, N. Energy harvesting from the nonlinear oscillations of magnetic levitation. J. Sound Vib. 2009, 319, 515-530. [CrossRef]

81. Mahmoudi, S.; Kacem, N.; Bouhaddi, N. Enhancement of the performance of a hybrid nonlinear vibration energy harvester based on piezoelectric and electromagnetic transductions. Smart Mater. Struct. 2014, 23, 075024. [CrossRef]

82. Abed, I.; Kacem, N.; Bouhaddi, N.; Bouazizi, M.L. Multi-modal vibration energy harvesting approach based on nonlinear oscillator arrays under magnetic levitation. Smart Mater. Struct. 2016, 25, 025018. [CrossRef]

83. Yang, B.; Lee, C.; Xiang, W.; Xie, J.; He, J.H.; Kotlanka, R.K.; Low, S.P.; Feng, H. Electromagnetic energy harvesting from vibrations of multiple frequencies. J. Micromech. Microeng. 2009, 19, 035001. [CrossRef]

84. Sari, I.; Balkan, T.; Kulah, H. An electromagnetic micro power generator for wideband environmental vibrations. Sens. Actuators A Phys. 2008, 145, 405-413. [CrossRef]

85. Abed, I.; Kacem, N.; Bouazizi, M.; Bouhaddi, N. Nonlinear 2-dofs vibration energy harvester based on magnetic levitation. In Shock \& Vibration, Aircraft/Aerospace, and Energy Harvesting; Springer: Berlin, Germnay, 2015; Volume 9, pp. 39-45.

86. Melilli, G.; Lairez, D.; Gorse, D.; Garcia-Caurel, E.; Peinado, A.; Cavani, O.; Boizot, B.; Clochard, M.C. Conservation of the piezoelectric response of PVDF films under irradiation. Radiat. Phys. Chem. 2018, 142, 54-59. [CrossRef]

87. Liang, F.; Zhao, D.; Jiang, D.; Liu, Z.; Zhu, J.; Chen, P.; Yang, J.; Liu, W.; Liu, S.; Xing, Y.; et al. Improvement of slope efficiency of GaN-Based blue laser diodes by using asymmetric MQW and InxGa1-xN lower waveguide. J. Alloys Compd. 2018, 731, 243-247. [CrossRef]

88. Al Ahmad, M.; Allataifeh, A. Piezoelectric-Based Energy Harvesting for Smart City Application. In Information Innovation Technology in Smart Cities; Springer: Berlin, Germnay, 2018; pp. 343-356.

89. Lee, H.; Sharpes, N.; Abdelmoula, H.; Abdelkefi, A.; Priya, S. Higher power generation from torsion-dominant mode in a zigzag shaped two-dimensional energy harvester. Appl. Energy 2018, 216, 494-503. [CrossRef]

90. Naseer, R.; Abdelkefi, A.; Dai, H.; Wang, L. Characteristics and comparative analysis of monostable and bistable piezomagnetoelastic energy harvesters under vortex-induced vibrations. In Proceedings of the 2018 AIAA/ASCE/AHS/ASC Structures, Structural Dynamics, and Materials Conference, Kissimmee, FL, USA, 8-12 January 2018; p. 1959.

91. Dai, H.; Yang, Y.; Abdelkefi, A.; Wang, L. Nonlinear analysis and characteristics of inductive galloping energy harvesters. Commun. Nonlinear Sci. Numer. Simul. 2018, 59, 580-591. [CrossRef]

92. Fang, F.; Xia, G.; Wang, J. Nonlinear dynamic analysis of cantilevered piezoelectric energy harvesters under simultaneous parametric and external excitations. Acta Mech. Sin. 2018, 34, 561-577. [CrossRef] 
93. Xiang, H.J.; Zhang, Z.; Shi, Z.; Li, H. Reduced-order Modeling of Piezoelectric Energy Harvesters with Nonlinear Circuits under Complex Conditions. Smart Mater. Struct. 2018, 27, 045004. [CrossRef]

94. Xie, Z.; Kitio Kwuimy, C.; Wang, Z.; Huang, W. A piezoelectric energy harvester for broadband rotational excitation using buckled beam. AIP Adv. 2018, 8, 015125. [CrossRef]

95. Li, H.T.; Qin, W.Y.; Zu, J.; Yang, Z. Modeling and experimental validation of a buckled compressive-mode piezoelectric energy harvester. Nonlinear Dyn. 2018, 92, 1761-1780. [CrossRef]

96. Du, S.; Jia, Y.; Seshia, A.A. Piezoelectric vibration energy harvesting: A connection configuration scheme to increase operational range and output power. J. Intell. Mater. Syst. Struct. 2017, 28, 1905-1915. [CrossRef]

97. Wang, X.; Chen, C.; Wang, N.; San, H.; Yu, Y.; Halvorsen, E.; Chen, X. A frequency and bandwidth tunable piezoelectric vibration energy harvester using multiple nonlinear techniques. Appl. Energy 2017, 190, 368-375. [CrossRef]

98. Phan, T.D.; Springer, P.; Liebich, R. Numerical Investigation of an Elastomer-Piezo-Adaptive Blade for Active Flow Control of a Nonsteady Flow Field Using Fluid-Structure Interaction Simulations. J. Turbomach. 2017, 139, 091004. [CrossRef]

99. Ghalambaz, M.; Jamesahar, E.; Ismael, M.A.; Chamkha, A.J. Fluid-structure interaction study of natural convection heat transfer over a flexible oscillating fin in a square cavity. Int. J. Therm. Stress. 2017, 111, 256-273. [CrossRef]

100. Farajpour, A.; Rastgoo, A.; Mohammadi, M. Vibration, buckling and smart control of microtubules using piezoelectric nanoshells under electric voltage in thermal environment. Phys. B Condens. Matter 2017, 509, 100-114. [CrossRef]

101. Abdolvand, R.; Fatemi, H.; Moradian, S. Quality factor and coupling in piezoelectric mems resonators. In Piezoelectric MEMS Resonators; Springer: Berlin, Germnay, 2017; pp. 133-152.

102. Rasani, M.R.; Aldlemy, M.S.; Harun, Z. Fluid-structure interaction analysis of rear spoiler vibration for energy harvesting potential. J. Mech. Eng. Sci. 2017, 11, 2415-2427. [CrossRef]

103. Hoshyarmanesh, H.; Abbasi, A. Structural health monitoring of rotary aerospace structures based on electromechanical impedance of integrated piezoelectric transducers. J. Intell. Mater. Syst. Struct. 2017, 29, 1799-1817. [CrossRef]

104. Panda, P. Piezoceramic Materials and Devices for Aerospace Applications. In Aerospace Materials and Material Technologies; Springer: Berlin, Germnay, 2017; pp. 501-518.

105. Tang, D.; Dowell, E. Aeroelastic response and energy harvesting from a cantilevered piezoelectric laminated plate. J. Fluids Struct. 2018, 76, 14-36. [CrossRef]

106. De Sousa, V.C.; Silva, T.M.P.; Junior, C.D.M. Aeroelastic flutter enhancement by exploiting the combined use of shape memory alloys and nonlinear piezoelectric circuits. J. Sound Vib. 2017, 407, 46-62. [CrossRef]

107. Zhao, L.; Yang, Y. An impact-based broadband aeroelastic energy harvester for concurrent wind and base vibration energy harvesting. Appl. Energy 2018, 212, 233-243. [CrossRef]

108. Zakaria, M.Y.; Al-Haik, M.Y.; Hajj, M.R. Experimental analysis of energy harvesting from self-induced flutter of a composite beam. Appl. Phys. Lett. 2015, 107, 023901. [CrossRef]

109. John, C.W.; Churchill, M.; Gast, D.R.; McCreight, J.N.; London, B.J. Fluid Flow Structure and Method of Use for Continuous Motion Washing Machine. US Patent 9,750,388, 5 September 2017.

110. Blake, W.K. Mechanics of Flow-Induced Sound and Vibration, Volume 2: Complex Flow-Structure Interactions; Academic Press: Cambridge, MA, USA, 2017.

111. Pourkiaee, S.M.; Khadem, S.E.; Shahgholi, M.; Bab, S. Nonlinear modal interactions and bifurcations of a piezoelectric nanoresonator with three-to-one internal resonances incorporating surface effects and van der Waals dissipation forces. Nonlinear Dyn. 2017, 88, 1785-1816. [CrossRef]

112. Zhou, Y.; Zhang, W. Double Hopf bifurcation of composite laminated piezoelectric plate subjected to external and internal excitations. Appl. Math. Mech. 2017, 38, 689-706. [CrossRef]

113. Ashoori, A.; Vanini, S.S. Vibration of circular functionally graded piezoelectric plates in pre-/postbuckled configurations of bifurcation/limit load buckling. Acta Mech. 2017, 228, 2945-2964. [CrossRef]

114. Verstraelen, E.; Kerschen, G.; Dimitriadis, G. Flutter and limit cycle oscillation suppression using linear and nonlinear tuned vibration absorbers. In Shock \& Vibration, Aircraft/Aerospace, Energy Harvesting, Acoustics $\mathcal{E}$ Optics, Volume 9; Springer: Berlin, Germnay, 2017; pp. 301-313. 
115. Chatterjee, P.; Mazzoleni, N.; Bryant, M. Experimental investigation of flow induced limit cycle oscillations in a tensioned ribbon. In Active and Passive Smart Structures and Integrated Systems 2017; International Society for Optics and Photonics: Bellingham, WA, USA, 2017; Volume 10164, p. 1016402.

116. Zhang, L.; Chen, F. Stability and bifurcation for limit cycle oscillations of an airfoil with external store. Nonlinear Dyn. 2017, 88, 165-187. [CrossRef]

117. Bukland, J.R.; Hatfield, S.A.; Weichert, S.A.; Pooley, D.M. Acoustic-Resonance Fluid Pump. US Patent Application No. 15/104,080, 5 January 2017.

118. Wang, G.; Tan, C.; Li, F. A contact resonance viscometer based on the electromechanical impedance of a piezoelectric cantilever. Sens. Actuators A Phys. 2017, 267, 401-408. [CrossRef]

119. Eid, F.; Liff, S.M.; Oster, S.N.; Sounart, T.L.; Dogiamis, G.C.; Elsherbini, A.A.; Swan, J.M. Piezoelectric Package-Integrated Synthetic Jet Devices. U.S. Patent 9,902,152, 27 February 2018.

120. An, X.; Song, B.; Tian, W.; Ma, C. Numerical simulation of Vortex Induced Piezoelectric Energy Converter (VIPEC) based on coupled fluid, structure and piezoelectric interaction. In Proceedings of the IEEE OCEANS 2017, Aberdeen, Scotland, 19-22 June 2017; pp. 1-5.

121. Franzini, G.R.; Bunzel, L.O. A numerical investigation on piezoelectric energy harvesting from Vortex-Induced Vibrations with one and two degrees of freedom. J. Fluids Struct. 2018, 77, 196-212. [CrossRef]

122. Tsushima, N.; Su, W. Flutter suppression for highly flexible wings using passive and active piezoelectric effects. Aerosp. Sci. Technol. 2017, 65, 78-89. [CrossRef]

123. Yan, Z.; Sun, W.; Tan, T.; Huang, W. Nonlinear analysis of galloping piezoelectric energy harvesters with inductive-resistive circuits for boundaries of analytical solutions. Commun. Nonlinear Sci. Numer. Simul. 2018, 62, 90-116. [CrossRef]

124. Abdelkefi, A. Aeroelastic energy harvesting: A review. Int. J. Eng. Sci. 2016, 100, 112-135. [CrossRef]

125. Lampani, L.; Grillo, R.; Gaudenzi, P. Finite element models of piezoelectric actuation for active flow control. Acta Astronaut. 2012, 71, 129-138. [CrossRef]

126. Mehmood, A.; Abdelkefi, A.; Hajj, M.; Nayfeh, A.; Akhtar, I.; Nuhait, A. Piezoelectric energy harvesting from vortex-induced vibrations of circular cylinder. J. Sound Vib. 2013, 332, 4656-4667. [CrossRef]

127. Dai, H.; Abdelkefi, A.; Wang, L. Piezoelectric energy harvesting from concurrent vortex-induced vibrations and base excitations. Nonlinear Dyn. 2014, 77, 967-981. [CrossRef]

128. Dai, H.; Abdelkefi, A.; Wang, L. Theoretical modeling and nonlinear analysis of piezoelectric energy harvesting from vortex-induced vibrations. J. Intell. Mater. Syst. Struct. 2014, 25, 1861-1874. [CrossRef]

129. Ashok, P.; Chandra, C.J.; Neeraj, P.; Santhosh, B. Parametric Study and Optimization of a Piezoelectric Energy Harvester from Flow Induced Vibration. In IOP Conference Series: Materials Science and Engineering; IOP Publishing: Bristol, UK, 2018; Volume 310, p. 012110.

130. Arionfard, H.; Nishi, Y. Experimental investigation of a drag assisted vortex-induced vibration energy converter. J. Fluids Struct. 2017, 68, 48-57. [CrossRef]

131. Nishi, Y.; Fukuda, K.; Shinohara, W. Experimental energy harvesting from fluid flow by using two vibrating masses. J. Sound Vib. 2017, 394, 321-332. [CrossRef]

132. Soti, A.K.; Thompson, M.C.; Sheridan, J.; Bhardwaj, R. Harnessing electrical power from vortex-induced vibration of a circular cylinder. J. Fluids Struct. 2017, 70, 360-373. [CrossRef]

133. Zhang, L.; Abdelkefi, A.; Dai, H.; Naseer, R.; Wang, L. Design and experimental analysis of broadband energy harvesting from vortex-induced vibrations. J. Sound Vib. 2017, 408, 210-219. [CrossRef]

134. Bunzel, L.O.; Franzini, G.R. Numerical studies on piezoelectric energy harvesting from vortex-induced vibrations considering cross-wise and in-line oscillations. In Proceedings of the 9th European Nonlinear Dynamics Conference-ENOC2017, Budapest, Hungary, 25-30 June 2017.

135. Guimarães, T.A.; Rade, D.A.; Cesnik, C.E. Active Flutter Suppression on Composite Tow Steered Panels based on Piezoelectric Actuation. In Proceedings of the 2018 AIAA/ASCE/AHS/ASC Structures, Structural Dynamics, and Materials Conference, Kissimmee, FL, USA, 8-12 January 2018; p. 0188.

136. Han, J.H.; Tani, J.; Qiu, J. Active flutter suppression of a lifting surface using piezoelectric actuation and modern control theory. J. Sound Vib. 2006, 291, 706-722. [CrossRef]

137. Bibo, A.; Abdelkefi, A.; Daqaq, M.F. Modeling and characterization of a piezoelectric energy harvester under combined aerodynamic and base excitations. J. Vib. Acoust. 2015, 137, 031017. [CrossRef] 
138. Abdelkefi, A.; Nayfeh, A.H.; Hajj, M. Modeling and analysis of piezoaeroelastic energy harvesters. Nonlinear Dyn. 2012, 67, 925-939. [CrossRef]

139. Riso, C.; Mastroddi, F.; Cesnik, C.E. Coupled Flight Dynamics and Aeroelasticity of Very Flexible Aircraft Based on Commercial Finite Element Solvers. In Proceedings of the 2018 AIAA/ASCE/AHS/ASC Structures, Structural Dynamics, and Materials Conference, Kissimmee, FL, USA, 8-12 January 2018; p. 1685.

140. Wang, X.; Wan, Z.; Liu, Z.; Yang, C. Integrated optimization on aerodynamics-structure coupling and flight stability of a large airplane in preliminary design. Chin. J. Aeronaut. 2018, 31, 1258-1272. [CrossRef]

141. Dessi, D.; Mastroddi, F. Limit-cycle stability reversal via singular perturbation and wing-flap flutter. J. Fluids Struct. 2004, 19, 765-783. [CrossRef]

142. Mastroddi, F.; Morino, L. Limit-cycle taming by nonlinear control with applications to flutter. Aeronaut. J. 1996, 100, 389-396.

143. Crema, L.B.; Mastroddi, F.; Coppotelli, G. Aeroelastic sensitivity analyses for flutter speed and gust response. J. Aircr. 2000, 37, 172-180. [CrossRef]

144. Shoele, K.; Mittal, R. Energy harvesting by flow-induced flutter in a simple model of an inverted piezoelectric flag. J. Fluid Mech. 2016, 790, 582-606. [CrossRef]

145. Dowell, E.H.; Tang, D. Nonlinear aeroelasticity and unsteady aerodynamics. AIAA J. 2002, 40, $1697-1707$. [CrossRef]

146. Gilliatt, H.C.; Strganac, T.W.; Kurdila, A.J. An investigation of internal resonance in aeroelastic systems. Nonlinear Dyn. 2003, 31, 1-22. [CrossRef]

147. Liu, L.; Wong, Y.; Lee, B. Application of the centre manifold theory in non-linear aeroelasticity. J. Sound Vib. 2000, 234, 641-659. [CrossRef]

148. Abdelkefi, A.; Hajj, M.R.; Nayfeh, A.H. Sensitivity analysis of piezoaeroelastic energy harvesters. J. Intell. Mater. Syst. Struct. 2012, 23, 1523-1531. [CrossRef]

149. Eugeni, M.; Elahi, H.; Lampani, L.; Gaudenzi, P. Modeling and Design of a Nonlinear Aeroelastic Energy Harvester. In Proceedings of the 68th International Astronautical Congress (IAC), Adelaide, Australia, 25-29 September 2017.

150. Bahaadini, R.; Hosseini, M.; Jamali, B. Flutter and divergence instability of supported piezoelectric nanotubes conveying fluid. Phys. B Condens. Matter 2018, 529, 57-65. [CrossRef]

151. Song, Z.G.; Li, F.M.; Carrera, E.; Hagedorn, P. A new method of smart and optimal flutter control for composite laminated panels in supersonic airflow under thermal effects. J. Sound Vib. 2018, 414, 218-232. [CrossRef]

152. Dai, H.; Abdelkefi, A.; Javed, U.; Wang, L. Modeling and performance of electromagnetic energy harvesting from galloping oscillations. Smart Mater. Struct. 2015, 24, 045012. [CrossRef]

153. Vicente-Ludlam, D.; Barrero-Gil, A.; Velazquez, A. Enhanced mechanical energy extraction from transverse galloping using a dual mass system. J. Sound Vib. 2015, 339, 290-303. [CrossRef]

154. Tang, L.; Zhao, L.; Yang, Y.; Lefeuvre, E. Equivalent circuit representation and analysis of galloping-based wind energy harvesting. IEEE Trans. Mech. 2015, 20, 834-844. [CrossRef]

155. Petrini, F.; Gkoumas, K. Piezoelectric energy harvesting from vortex shedding and galloping induced vibrations inside HVAC ducts. Energy Build. 2018, 158, 371-383. [CrossRef]

156. Bashir, M.; Rajendran, P.; Khan, S. Energy Harvesting from Aerodynamic Instabilities: Current prospect and Future Trends. In IOP Conference Series: Materials Science and Engineering; IOP Publishing: Bristol, UK, 2018; Volume 290, p. 012054.

157. Maruai, N.M.; Ali, M.S.M.; Ismail, M.H.; Zaki, S.A. Flow-induced vibration of a square cylinder and downstream flat plate associated with micro-scale energy harvester. J. Wind Eng. Ind. Aerodyn. 2018, 175, 264-282. [CrossRef]

158. Abdelkefi, A.; Hajj, M.; Nayfeh, A. Piezoelectric energy harvesting from transverse galloping of bluff bodies. Smart Mater. Struct. 2012, 22, 015014. [CrossRef]

159. Abdelkefi, A.; Yan, Z.; Hajj, M.R. Modeling and nonlinear analysis of piezoelectric energy harvesting from transverse galloping. Smart Mater. Struct. 2013, 22, 025016. [CrossRef]

160. Barrero-Gil, A.; Alonso, G.; Sanz-Andres, A. Energy harvesting from transverse galloping. J. Sound Vib. 2010, 329, 2873-2883. [CrossRef]

161. Jung, H.J.; Lee, S.W. The experimental validation of a new energy harvesting system based on the wake galloping phenomenon. Smart Mater. Struct. 2011, 20, 055022. [CrossRef] 
162. Abdelkefi, A.; Scanlon, J.; McDowell, E.; Hajj, M.R. Performance enhancement of piezoelectric energy harvesters from wake galloping. Appl. Phys. Lett. 2013, 103, 033903. [CrossRef]

163. Zhu, H.; Zhao, Y.; Zhou, T. CFD analysis of energy harvesting from flow induced vibration of a circular cylinder with an attached free-to-rotate pentagram impeller. Appl. Energy 2018, 212, 304-321. [CrossRef]

164. Abdelkefi, A.; Hajj, M.R.; Nayfeh, A.H. Power harvesting from transverse galloping of square cylinder. Nonlinear Dyn. 2012, 70, 1355-1363. [CrossRef]

165. Zhao, L.; Tang, L.; Yang, Y. Synchronized charge extraction in galloping piezoelectric energy harvesting. J. Intell. Mater. Syst. Struct. 2016, 27, 453-468. [CrossRef]

166. Tan, T.; Yan, Z. Electromechanical decoupled model for cantilever-beam piezoelectric energy harvesters with inductive-resistive circuits and its application in galloping mode. Smart Mater. Struct. 2017, 26, 035062. [CrossRef]

167. Ewere, F.; Wang, G.; Frendi, A. Experimental Investigation of a Bioinspired Bluff-Body Effect on Galloping Piezoelectric Energy-Harvester Performance. AIAA J. 2017, 56, 1284-1287. [CrossRef]

168. Tan, T.; Yan, Z.; Lei, H. Optimization and performance comparison for galloping-based piezoelectric energy harvesters with alternating-current and direct-current interface circuits. Smart Mater. Struct. 2017, 26, 075007. [CrossRef]

169. Naseer, R.; Dai, H.; Abdelkefi, A.; Wang, L. Piezomagnetoelastic energy harvesting from vortex-induced vibrations using monostable characteristics. Appl. Energy 2017, 203, 142-153. [CrossRef]

170. Akaydin, H.D.; Elvin, N.; Andreopoulos, Y. Energy harvesting from highly unsteady fluid flows using piezoelectric materials. J. Intell. Mater. Syst. Struct. 2010, 21, 1263-1278. [CrossRef]

171. Akaydin, H.; Elvin, N.; Andreopoulos, Y. The performance of a self-excited fluidic energy harvester. Smart Mater. Struct. 2012, 21, 025007. [CrossRef]

172. Bryant, M.; Garcia, E. Modeling and testing of a novel aeroelastic flutter energy harvester. J. Vib. Acoust. 2011, 133, 011010. [CrossRef]

173. Abdelkefi, A.; Vasconcellos, R.; Nayfeh, A.H.; Hajj, M.R. An analytical and experimental investigation into limit-cycle oscillations of an aeroelastic system. Nonlinear Dyn. 2013, 71, 159-173. [CrossRef]

174. Sirohi, J.; Mahadik, R. Harvesting wind energy using a galloping piezoelectric beam. J. Vib. Acoust. 2012, 134, 011009. [CrossRef]

175. Yang, Y.; Zhao, L.; Tang, L. Comparative study of tip cross-sections for efficient galloping energy harvesting. Appl. Phys. Lett. 2013, 102, 064105. [CrossRef]

176. Daqaq, M.F. Characterizing the response of galloping energy harvesters using actual wind statistics. J. Sound Vib. 2015, 357, 365-376. [CrossRef]

177. Giacomello, A.; Porfiri, M. Underwater energy harvesting from a heavy flag hosting ionic polymer metal composites. J. Appl. Phys. 2011, 109, 084903. [CrossRef]

178. Aramendia, I.; Fernandez-Gamiz, U.; Zulueta Guerrero, E.; Lopez-Guede, J.M.; Sancho, J. Power Control Optimization of an Underwater Piezoelectric Energy Harvester. Appl. Sci. 2018, 8, 389. [CrossRef]

179. Dunnmon, J.; Stanton, S.; Mann, B.; Dowell, E. Power extraction from aeroelastic limit cycle oscillations. J. Fluids Struct. 2011, 27, 1182-1198. [CrossRef]

180. Li, S.; Lipson, H. Vertical-stalk flapping-leaf generator for wind energy harvesting. In ASME 2009 Conference on Smart Materials, Adaptive Structures and Intelligent Systems; American Society of Mechanical Engineers: New York, NY, USA, 2009; pp. 611-619.

181. Li, S.; Yuan, J.; Lipson, H. Ambient wind energy harvesting using cross-flow fluttering. J. Appl. Phys. 2011, 109, 026104 . [CrossRef]

182. Kwon, S.D. A T-shaped piezoelectric cantilever for fluid energy harvesting. Appl. Phys. Lett. 2010, 97, 164102. [CrossRef]

183. Shukla, S.; Govardhan, R.; Arakeri, J. Flow over a cylinder with a hinged-splitter plate. J. Fluids Struct. 2009, 25, 713-720. [CrossRef]

184. Williamson, C.; Govardhan, R. Vortex-induced vibrations. Annu. Rev. Fluid Mech. 2004, 36, 413-455. [CrossRef]

185. Hobeck, J.; Inman, D. Artificial piezoelectric grass for energy harvesting from turbulence-induced vibration. Smart Mater. Struct. 2012, 21, 105024. [CrossRef]

186. Hobeck, J.; Inman, D. A distributed parameter electromechanical and statistical model for energy harvesting from turbulence-induced vibration. Smart Mater. Struct. 2014, 23, 115003. [CrossRef] 
187. Anton, S.R.; Inman, D.J. Vibration energy harvesting for unmanned aerial vehicles. In Active and Passive Smart Structures and Integrated Systems 2008; International Society for Optics and Photonics: Bellingham, WA, USA, 2008; Volume 6928, p. 692824.

188. Oh, S.; Han, H.; Han, S.; Lee, J.; Chun, W. Development of a tree-shaped wind power system using piezoelectric materials. Int. J. Energy Res. 2010, 34, 431-437. [CrossRef]

189. Priya, S. Modeling of electric energy harvesting using piezoelectric windmill. Appl. Phys. Lett. 2005, 87, 184101. [CrossRef]

190. Ju, S.; Ji, C.H. Impact-based piezoelectric vibration energy harvester. Appl. Energy 2018, 214, $139-151$. [CrossRef]

191. Izadgoshasb, I.; Lim, Y.Y.; Lake, N.; Tang, L.; Padilla, R.V.; Kashiwao, T. Optimizing orientation of piezoelectric cantilever beam for harvesting energy from human walking. Energy Convers. Manag. 2018, 161, 66-73. [CrossRef]

192. Kim, M.O.; Pyo, S.; Oh, Y.; Kang, Y.; Cho, K.H.; Choi, J.; Kim, J. Flexible and multi-directional piezoelectric energy harvester for self-powered human motion sensor. Smart Mater. Struct. 2018, 27, 035001. [CrossRef]

193. Helal, M.H. Evaluation of osse-ous response after placement of experimental implants in femur of diabetic rabbits using piezoelectric osteotomy. Int. J. Dent. Oral Heal. 2018, 4, 1-7.

194. Tsubota, Y.; Suzuki, A.; Terada, T.; Wu, W.; Yamanaka, K.; Sasaki, K.; Kobayashi, M.; Kawabata, K.I. Animal study of high-speed iterative refraction calibration method for ultrasound computed tomography. In Medical Imaging 2018: Ultrasonic Imaging and Tomography; International Society for Optics and Photonics: Bellingham, WA, USA, 2018; Volume 10580.

195. Yu, X.; Wang, H.; Ning, X.; Sun, R.; Albadawi, H.; Salomao, M.; Silva, A.C.; Yu, Y.; Tian, L.; Koh, A.; et al. Needle-shaped ultrathin piezoelectric microsystem for guided tissue targeting via mechanical sensing. Nat. Biomed. Eng. 2018, 2, 165-172. [CrossRef]

196. Lau, J.Y.; Liang, W.; Liaw, H.C.; Tan, K.K. Sliding Mode Disturbance Observer-based Motion Control for a Piezoelectric Actuator-based Surgical Device. Asian J. Control 2018, 20. [CrossRef]

197. Yeoh, I.L.; Reinhall, P.G.; Seibel, E.J.; Kundrat, M.J. Adaptive Control of a Fiber Scanner With Piezoelectric Sensing. US Patent 9,872,606, 23 January 2018.

198. Adams, M.; Adams, R.; Yaqub, R. Integrated Mobile Phone Case and Charger. US Patent 9,698,623, 4 July 2017.

199. Anwar, M.; Hakim, L.; Nadzri, N. Prototype of a low power energy harvesting using piezoelectric transducer for common stationary workout. In Proceedings of the 2017 IEEE 4th International Conference on Smart Instrumentation, Measurement and Application (ICSIMA), Putrajaya, Malaysia, 28-30 November 2017; pp. 1-4.

200. Wang, X. Implantable Flexible Nanogenerators for Biomechanical Energy Harvesting; Meeting Abstracts; The Electrochemical Society: Pennington, NJ, USA, 2018; pp. 1492.

201. Todaro, M.T.; Guido, F.; Algieri, L.; Mastronardi, V.M.; Desmaële, D.; Epifani, G.; De Vittorio, M. Biocompatible, flexible and compliant energy harvesters based on piezoelectric thin films. IEEE Trans. Nanotechnol. 2018, 17, 220-230. [CrossRef]

202. Safaei, M.; Ponder, R.I.; Anton, S.R. Detection of compartmental forces and location of contact areas with piezoelectric transducers in total knee arthroplasty. In Active and Passive Smart Structures and Integrated Systems XII; International Society for Optics and Photonics: Bellingham, WA, USA, 2018; Volume 10595, p. 105951Q.

203. Lemmers, G.; Heijmans, M.; Scafoglieri, A.; Buyl, R.; Staal, J.; Schmitt, M.; Cattrysse, E. Three-dimensional kinematics of the cervical spine using an electromagnetic tracking device. Differences between healthy subjects and subjects with non-specific neck pain and the effect of age. Clin. Biomech. 2018, 54, 111-117. [CrossRef] [PubMed]

204. Yin, Y.; Wang, J.; Zhao, S.; Fan, W.; Zhang, X.; Zhang, C.; Xing, Y.; Li, C. Stretchable and Tailorable Triboelectric Nanogenerator Constructed by Nanofibrous Membrane for Energy Harvesting and Self-Powered Biomechanical Monitoring. Adv. Mater. Technol. 2018, 3, 1700370. [CrossRef]

205. Granstrom, J.; Feenstra, J.; Sodano, H.A.; Farinholt, K. Energy harvesting from a backpack instrumented with piezoelectric shoulder straps. Smart Mater. Struct. 2007, 16, 1810. [CrossRef]

206. Feenstra, J.; Granstrom, J.; Sodano, H. Energy harvesting through a backpack employing a mechanically amplified piezoelectric stack. Mech. Syst. Signal Process. 2008, 22, 721-734. [CrossRef] 
207. Shenck, N.S.; Paradiso, J.A. Energy scavenging with shoe-mounted piezoelectrics. IEEE Micro 2001, 21, 30-42. [CrossRef]

208. Howells, C.A. Piezoelectric energy harvesting. Energy Convers. Manag. 2009, 50, 1847-1850. [CrossRef]

209. Fan, K.; Liu, Z.; Liu, H.; Wang, L.; Zhu, Y.; Yu, B. Scavenging energy from human walking through a shoe-mounted piezoelectric harvester. Appl. Phys. Lett. 2017, 110, 143902. [CrossRef]

210. Rocha, J.G.; Goncalves, L.M.; Rocha, P.; Silva, M.P.; Lanceros-Mendez, S. Energy harvesting from piezoelectric materials fully integrated in footwear. IEEE Trans. Ind. Electron. 2010, 57, 813-819. [CrossRef]

211. Zhao, J.; You, Z. A shoe-embedded piezoelectric energy harvester for wearable sensors. Sensors 2014, 14, 12497-12510. [CrossRef] [PubMed]

212. Jung, W.S.; Lee, M.J.; Kang, M.G.; Moon, H.G.; Yoon, S.J.; Baek, S.H.; Kang, C.Y. Powerful curved piezoelectric generator for wearable applications. Nano Energy 2015, 13, 174-181. [CrossRef]

213. Kuang, Y.; Zhu, M. Characterisation of a knee-joint energy harvester powering a wireless communication sensing node. Smart Mater. Struct. 2016, 25, 055013. [CrossRef]

214. Kuang, Y.; Yang, Z.; Zhu, M. Design and characterisation of a piezoelectric knee-joint energy harvester with frequency up-conversion through magnetic plucking. Smart Mater. Struct. 2016, 25, 085029. [CrossRef]

215. Kymissis, J.; Kendall, C.; Paradiso, J.; Gershenfeld, N. Parasitic power harvesting in shoes. In Proceedings of the Digest of Papers Second International Symposium on Wearable Computers, Pittsburgh, PA, USA, 19-20 October 1998; pp. 132-139.

216. Delnavaz, A.; Voix, J. Flexible piezoelectric energy harvesting from jaw movements. Smart Mater. Struct. 2014, 23, 105020. [CrossRef]

217. Choi, Y.M.; Lee, M.G.; Jeon, Y. Wearable Biomechanical Energy Harvesting Technologies. Energies 2017, 10, 1483. [CrossRef]

218. Nia, E.M.; Zawawi, N.A.W.A.; Singh, B.S.M. A review of walking energy harvesting using piezoelectric materials. In IOP Conference Series: Materials Science and Engineering; IOP Publishing: Bristol, UK, 2017; Volume 291, p. 012026.

219. Niu, P.; Chapman, P.; Riemer, R.; Zhang, X. Evaluation of motions and actuation methods for biomechanical energy harvesting. In Proceedings of the 2004 IEEE 35th Annual Power Electronics Specialists Conference PESC 04, Aachen, Germany, 20-25 June 2004; Volume 3, pp. 2100-2106.

220. Winter, D.A. Biomechanics and Motor Control of Human Movement, 4th ed.; John Wiley \& Sons: Hoboken, NJ, USA, 2009; pp. 82-106.

221. Riemer, R.; Shapiro, A. Biomechanical energy harvesting from human motion: Theory, state of the art, design guidelines, and future directions. J. Neuroeng. Rehabil. 2011, 8, 22. [CrossRef] [PubMed]

222. Renaud, M.; Fiorini, P.; van Schaijk, R.; Van Hoof, C. Harvesting energy from the motion of human limbs: the design and analysis of an impact-based piezoelectric generator. Smart Mater. Struct. 2009, 18, 035001. [CrossRef]

223. Bai, Y.; Tofel, P.; Hadas, Z.; Smilek, J.; Losak, P.; Skarvada, P.; Macku, R. Investigation of a cantilever structured piezoelectric energy harvester used for wearable devices with random vibration input. Mech. Syst. Signal Process. 2018, 106, 303-318. [CrossRef]

224. Singh, P.K.; Pandey, P.; Singh, A.P.; Mehra, V.S.; Ojha, A.; Scholar, U. Fabrication of Piezoelectric-Thermal Gloves. Int. J. Eng. Sci. 2016, 6, 5185-5187.

225. Halim, M.A.; Park, J.Y. Piezoelectric energy harvester using impact-driven flexible side-walls for human-limb motion. Microsyst. Technol. 2017, 24, 2099-2107. [CrossRef]

226. Li, J.; Wang, X. Research Update: Materials design of implantable nanogenerators for biomechanical energy harvesting. APL Mater. 2017, 5, 073801. [CrossRef] [PubMed]

227. Ansari, M.; Karami, M.A. Experimental investigation of fan-folded piezoelectric energy harvesters for powering pacemakers. Smart Mater. Struct. 2017, 26, 065001. [CrossRef] [PubMed]

228. Ahmed, R.; Mir, F.; Banerjee, S. A review on energy harvesting approaches for renewable energies from ambient vibrations and acoustic waves using piezoelectricity. Smart Mater. Struct. 2017, 26, 085031. [CrossRef]

229. Klein, W.P.; Díaz, S.A.; Buckhout-White, S.; Melinger, J.S.; Cunningham, P.D.; Goldman, E.R.; Ancona, M.G.; Kuang, W.; Medintz, I.L. Resonance Energy Transfer: Utilizing HomoFRET to Extend DNA-Scaffolded Photonic Networks and Increase Light-Harvesting Capability. Adv. Opt. Mater. 2018, 6, 1700679. [CrossRef]

230. Yang, Y.; Li, Y.; Guo, Y.; Xu, B.; Yang, T. Improved vibration-based energy harvesting by annular mass configuration of piezoelectric circular diaphragms. Smart Mater. Struct. 2018, 27, 035004. [CrossRef] 
231. Cooley, C.G.; Chai, T. Energy Harvesting From the Vibrations of Rotating Systems. J. Vib. Acoust. 2018, 140, 021010. [CrossRef]

232. Zhou, S.; Chen, W.; Malakooti, M.H.; Cao, J.; Inman, D.J. Design and modeling of a flexible longitudinal zigzag structure for enhanced vibration energy harvesting. J. Intell. Mater. Syst. Struct. 2017, 28, 367-380. [CrossRef]

233. Lee, M.S.; Yun, J.S.; Park, W.I.; Hong, Y.W.; Cho, J.H.; Paik, J.H.; Park, Y.H.; Son, C.M.; Jeong, Y.H. Fabrication and energy harvesting characteristics of unimorph piezoelectric cantilever generators with interdigitated electrode lead zirconate titanate laminates. Jpn. J. Appl. Phys. 2017, 56, 127101. [CrossRef]

234. Mukhanov, A.; Abdigaliyev, A.; Jangeldinov, B.; Zhussip, M.; Zhapparov, R.; Ruderman, A.; Adair, D. Development of a Design Tool for Optimization of Voltage Generation from a Bimorph Piezoelectric Cantilever Beam. Mater. Today Proc. 2017, 4, 4477-4490. [CrossRef]

235. Wu, W.H.; Kuo, K.C.; Lin, Y.H.; Tsai, Y.C. Non-contact magnetic cantilever-type piezoelectric energy harvester for rotational mechanism. Microelectron. Eng. 2018, 191, 16-19. [CrossRef]

236. Challa, V.R.; Prasad, M.; Shi, Y.; Fisher, F.T. A vibration energy harvesting device with bidirectional resonance frequency tunability. Smart Mater. Struct. 2008, 17, 015035. [CrossRef]

237. Harne, R.; Wang, K. A review of the recent research on vibration energy harvesting via bistable systems. Smart Mater. Struct. 2013, 22, 023001. [CrossRef]

238. Duggirala, R.; Polcawich, R.; Zakar, E.; Dubey, M.; Li, H.; Lal, A. MEMS radioisotope-powered piezoelectric $\mu$-power generator (RPG). In Proceedings of the 19th IEEE International Conference on Micro Electro Mechanical Systems MEMS 2006, Istanbul, Turkey, 22-26 January 2006; pp. 94-97.

239. Gao, X.; Shih, W.H.; Shih, W.Y. Vibration energy harvesting using piezoelectric unimorph cantilevers with unequal piezoelectric and nonpiezoelectric lengths. Appl. Phys. Lett. 2010, 97, 233503. [CrossRef] [PubMed]

240. Ng, T.H.; Liao, W.H. Feasibility study of a self-powered piezoelectric sensor. In Smart Structures and Materials 2004: Smart Electronics, MEMS, BioMEMS, and Nanotechnology; International Society for Optics and Photonics: Bellingham, WA, USA, 2004; Volume 5389, pp. 377-389.

241. Roundy, S.; Wright, P.K.; Rabaey, J. A study of low level vibrations as a power source for wireless sensor nodes. Comput. Commun. 2003, 26, 1131-1144. [CrossRef]

242. Roundy, S.; Wright, P.K. A piezoelectric vibration based generator for wireless electronics. Smart Mater. Struct. 2004, 13, 1131. [CrossRef]

243. Baker, J.; Roundy, S.; Wright, P. Alternative geometries for increasing power density in vibration energy scavenging for wireless sensor networks. In Proceedings of the 3rd International Energy Conversion Engineering Conference, San Francisco, CA, USA, 15-18 August 2005; p. 5617.

244. Leland, E.S.; Wright, P.K. Resonance tuning of piezoelectric vibration energy scavenging generators using compressive axial preload. Smart Mater. Struct. 2006, 15, 1413. [CrossRef]

245. Zheng, Q.; Xu, Y. Asymmetric air-spaced cantilevers for vibration energy harvesting. Smart Mater. Struct. 2008, 17, 055009. [CrossRef]

246. Lu, F.; Lee, H.; Lim, S. Modeling and analysis of micro piezoelectric power generators for micro-electromechanical-systems applications. Smart Mater. Struct. 2003, 13, 57. [CrossRef]

247. Choi, W.; Jeon, Y.; Jeong, J.H.; Sood, R.; Kim, S.G. Energy harvesting MEMS device based on thin film piezoelectric cantilevers. J. Electr. 2006, 17, 543-548. [CrossRef]

248. Tien, C.M.T.; Goo, N.S. Use of a piezocomposite generating element in energy harvesting. J. Intell. Mater. Syst. Struct. 2010, 21, 1427-1436. [CrossRef]

249. Kim, S.; Clark, W.W.; Wang, Q.M. Piezoelectric energy harvesting with a clamped circular plate: Analysis. J. Intell. Mater. Syst. Struct. 2005, 16, 847-854. [CrossRef]

250. Pan, D.; Ma, B.; Dai, F. Experimental investigation of broadband energy harvesting of a bi-stable composite piezoelectric plate. Smart Mater. Struct. 2017, 26, 035045. [CrossRef]

251. Wang, C.; Wang, S.; Li, Q.J.; Wang, X.; Gao, Z.; Zhang, L. Fabrication and performance of a power generation device based on stacked piezoelectric energy-harvesting units for pavements. Energy Convers. Manag. 2018, 163, 196-207. [CrossRef]

252. Swallow, L.; Luo, J.; Siores, E.; Patel, I.; Dodds, D. A piezoelectric fibre composite based energy harvesting device for potential wearable applications. Smart Mater. Struct. 2008, 17, 025017. [CrossRef]

253. Chen, X.; Xu, S.; Yao, N.; Shi, Y. 1.6 V nanogenerator for mechanical energy harvesting using PZT nanofibers. Nano Lett. 2010, 10, 2133-2137. [CrossRef] [PubMed] 
254. Gonella, S.; To, A.C.; Liu, W.K. Interplay between phononic bandgaps and piezoelectric microstructures for energy harvesting. J. Mech. Phys. Solids 2009, 57, 621-633. [CrossRef]

255. Liu, Z.; Zhang, X.; Mao, Y.; Zhu, Y.; Yang, Z.; Chan, C.T.; Sheng, P. Locally resonant sonic materials. Science 2000, 289, 1734-1736. [CrossRef] [PubMed]

256. Carrara, M.; Cacan, M.; Toussaint, J.; Leamy, M.; Ruzzene, M.; Erturk, A. Metamaterial-inspired structures and concepts for elastoacoustic wave energy harvesting. Smart Mater. Struct. 2013, 22, 065004. [CrossRef]

(C) 2018 by the authors. Licensee MDPI, Basel, Switzerland. This article is an open access article distributed under the terms and conditions of the Creative Commons Attribution (CC BY) license (http:/ / creativecommons.org/licenses/by/4.0/). 